\title{
EL ARTE RUPESTRE DE LA LOCALIDAD VIUDA QUENZANA REVISITADO (SANTA CRUZ, PATAGONIA ARGENTINA): NUEVAS EVIDENCIAS Y PRIMEROS RESULTADOS DE ANÁLISIS
}

\author{
REVISITING THE ROCK ART OF VIUDA QUENZANA ISANTA CRUZ, \\ ARGENTINIAN PATAGONIA): NEW EVIDENCE AND FIRST \\ ANALYSIS RESULTS
}

DANAE FIOREA \& Agustín ACEVEDo ${ }^{B}$

Se presentan los resultados del registro y análisis de 44 sitios arqueológicos de la localidad Viuda Quenzana, región extremo sur del macizo del Deseado (Patagonia, Argentina). Se caracteriza el tamaño, topografía, orientación, cantidad de paneles, motivos y tipos de motivos de cada sitio, las técnicas empleadas y el estado de conservación del arte. El trabajo propone un modelo de evaluación combinada del $\mathrm{N}$ de motivos y el $\mathrm{N}$ de tipos de motivos, con el objeto de analizar el grado de variabilidad y de recurrencias en la creación de distintos tipos y en la selección de algunos de ellos como casos que han concentrado las mayores frecuencias de producción de motivos.

Palabras clave: Arte rupestre, Viuda Quenzana, Patagonia, Producción, Repertorio.

The results are presented of the record and analyses of 44 archaeological sites of the locality of Viuda Quenzana, in the Southern Deseado Massif (Patagonia, Argentina). The size, topography, orientation, number of panels, number of motifs and number of motif types of each site are presented along with the techniques used and the state of conservation of the rock art. The paper proposes a combined evaluation model of the $N$ of motifs and $N$ of motif types, with the aim of analyzing the degree of variability and recurrences in the creation of different motif types and in the selection of specific motif types as cases which concentrated the highest production frequencies.

Keywords: Rock art, Viuda Quenzana, Patagonia, Production, Repertoire.

\section{INTRODUCCIÓN}

Este trabajo se propone dos objetivos complementarios. El primero es aportar información actualizada sobre el arte rupestre de la localidad arqueológica Viuda Quenzana, ubicada en el extremo sur del macizo del Deseado (ESMD), Provincia de Santa Cruz (Patagonia, Argentina) (fig. 1). Esta información ha sido generada a partir de la relocalización y relevamiento completo de sitios previamente conocidos, así como también a partir del registro y relevamiento de una importante cantidad de nuevos sitios, identificados a partir de prospecciones sistemáticas efectuadas en la localidad.

El segundo objetivo es analizar la producción de arte rupestre en Viuda Quenzana a partir de la integración de información respecto de: a) los soportes rocosos, b) los sitios, c) los motivos y d) las técnicas de ejecución. Dichos análisis se orientan a evaluar el emplazamiento espacial de los motivos en los soportes y en el paisaje, su distribución y densidad, así como la variabilidad en los repertorios artísticos. Asimismo, se propone una secuencia básica de producción de tipos de motivos a escala local. En tal sentido, la información generada permite profundizar nuestro conocimiento sobre la exis-

A Danae Fiore, conicet, UBA, Asociación de Investigaciones Antropológicas, Bartolomé Mitre 1131, piso 7, dpto. G, CP (1036) CABA. E-mail: danae_fiore@yahoo.es

B Agustín Acevedo, Conicet, Instituto Multidisciplinario de Historia y Ciencias Humanas, Saavedra 15, piso 5, CP (1083) CABA. E-mail: agustinacevedo2009@gmail.com

Recibido: septiembre 2017. Aceptado: octubre 2018. 


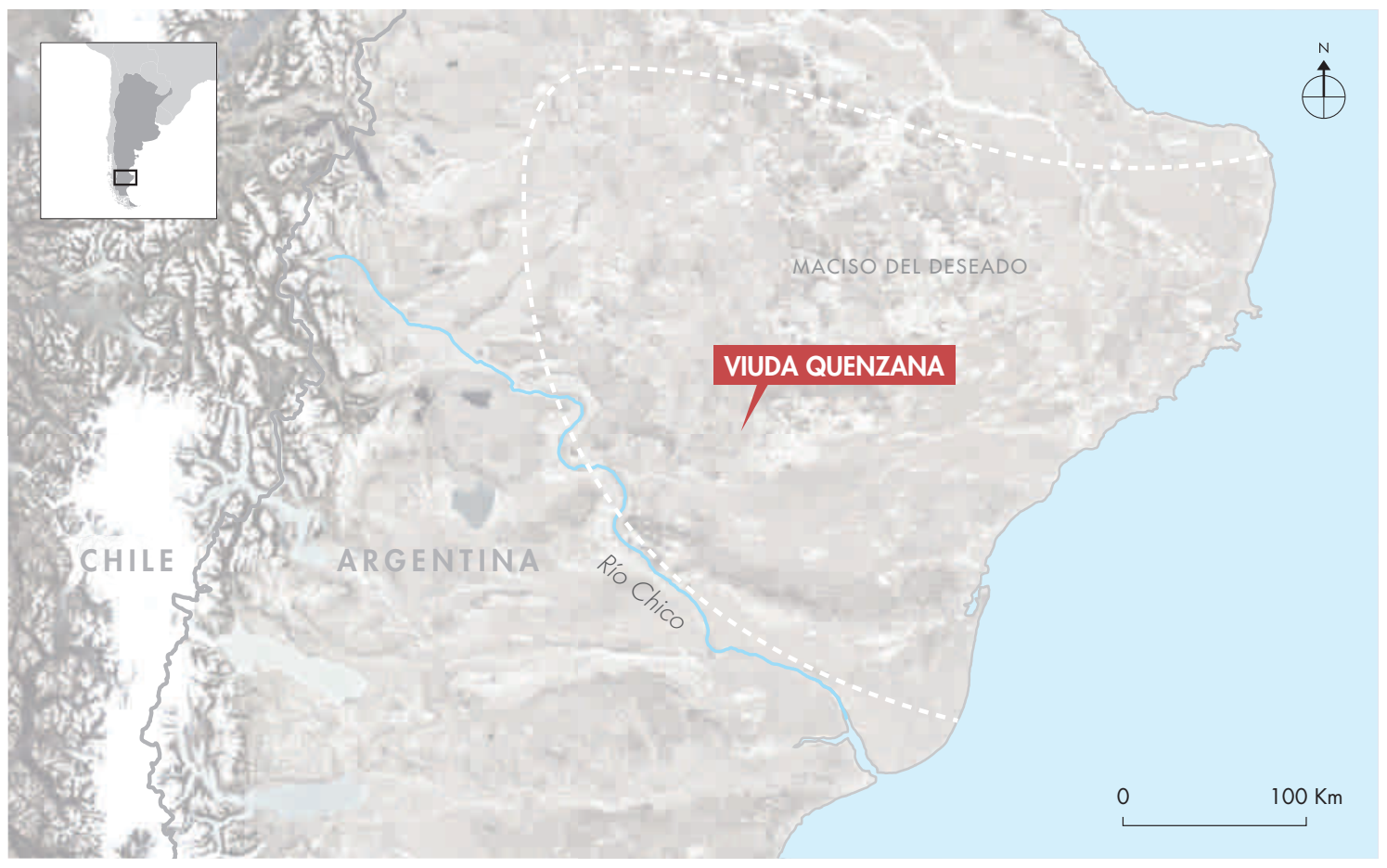

Figura 1. Ubicación geográfica de la localidad arqueológica Viuda Quenzana. Figure 1. Geographical location of Viuda Quenzana.

tencia de recurrencias y variaciones espacio-temporales acumuladas a lo largo de los procesos de creación de imágenes rupestres por grupos cazadores-recolectores en esta localidad.

\section{CARACTERIZACIÓN TOPOGRÁFICA Y GEOLÓGICA DE LA LOCALIDAD BAJO ESTUDIO}

La localidad arqueológica Viuda Quenzana se encuentra ubicada en el centro de la provincia de Santa Cruz (Patagonia argentina), al norte del Río Chico (fig. 1), cercana a localidades muy importantes para la arqueología de Patagonia por sus largas secuencias de ocupación y significativas producciones rupestres (e.g. La Gruta, La Martita, El Verano, La María y El Ceibo; Cardich 1987; Durán 1983-1985; Aguerre 1987, 2003; Franchomme 1987; Paunero et al. 2005; Franco et al. 2010, entre otros). La localidad comprende una superficie aproximada de $6 \mathrm{~km}^{2}$ y se caracteriza por una topografía de relieve irregular consistente de lomadas suaves interrumpidas por cañadones y zanjones de reducidas dimensiones que vierten sus aguas estacionales en depresiones sin desagüe (Panza \& Marín 1998). Dentro de esta topografía, los afloramientos de ignimbritas riolíticas de la Formación Chon Aike se presentan en forma de grandes paredones en el interior de cañadones y/o como asomos rocosos (o bardas) de medianas y pequeñas dimensiones (Panza \& Marín 1998). Un rasgo característico está dado por el abundante número de aleros, cuevas y cavidades que tienen lugar dentro de los afloramientos rocosos descriptos (Panza \& Marín 1998, Claudio Iglesias 2014, comunicación personal).

Los relevamientos sistemáticos del arte rupestre de Viuda Quenzana se han focalizado en tres sectores del espacio, lindantes entre sí, con características geomorfológicas, altitudinales y litológicas diferentes. Estos tres sectores se denominan: a) Bardas Altas; b) Bardas Intermedias y c) Cañadón Bajo (fig. 2). Bardas Altas e Intermedias consisten en asomos rocosos de ingnimbritas riolíticas de bajo grado de compactación, extendidos sobre los distintos planos de inclinación de una lomada suave (Claudio Iglesias 2014, comunicación personal). Por su parte, el sector Cañadón Bajo, consiste en un cañadón corto y angosto, de cauce efímero ${ }^{1}$ y orientación 


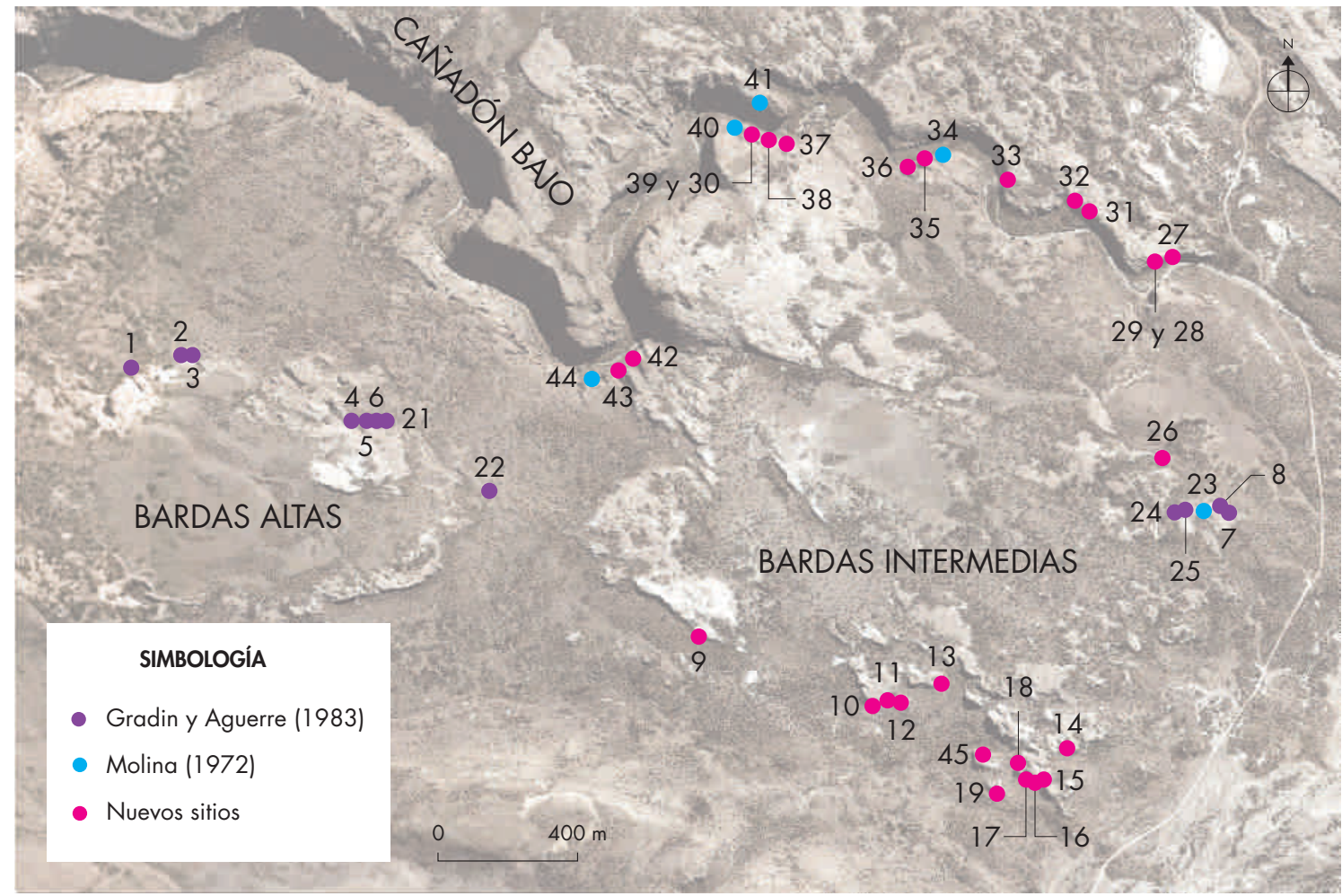

Figura 2. Sectorización y sitios rupestres de Viuda Quenzana. Figure 2. Sectors and rock art sites at Viuda Quenzana.

general oeste-este, conformado por grandes paredones de ignimbritas rióliticas de mayor grado de compactación (Claudio Iglesias 2014, comunicación personal). De esta manera, la diferencia entre los sectores de bardas es fundamentalmente altitudinal (Bardas Altas $=$ cotas entre 400 y $370 \mathrm{msnm}$; Bardas Intermedias $=$ cotas entre 330 y $300 \mathrm{msnm}$ ) y las diferencias entre el sector Cañadón Bajo y los sectores de bardas son -además de geomorfológicas- litológicas (ignimbritas de alto grado de compactación en el cañadón vs. bajo grado de compactación en las bardas).

La distinción entre los grados de compactación de las ignimbritas riolíticas que componen los afloramientos rocosos de los sectores de bardas (con bajo grado de compactación) y el sector de cañadón (con alto grado de compactación) es importante porque influye sobre la resistencia que cada uno de ellos ofrece frente a los procesos erosivos actuantes dentro de la localidad, principalmente la erosión catafilar (Claudio Iglesias 2014, comunicación personal). Puesto en términos sintéticos, la erosión catafilar consiste en la remoción progresiva de material rocoso de los afloramientos mediante des- camaciones concéntricas -en negativo- de láminas de roca de pocos milímetros de espesor, que generan como resultado la formación de oquedades, aleros y cuevas de techo semiesférico (Claudio Iglesias 2014, comunicación personal). Este proceso erosivo es el principal responsable de la abundante oferta de reparos rocosos disponibles en la localidad y, al mismo tiempo, de las malas condiciones de preservación del arte rupestre, producto de los desprendimientos de superficies de los soportes por exfoliación del sustrato rocoso.

\section{ANTECEDENTES}

El primer registro bibliográfico disponible de la localidad para el arte rupestre corresponde a una descripción realizada por Molina (1972) sobre distintos motivos pintados que observó en, al menos, cinco sitios localizados dentro del cañadón (actuales sitios VQ34, VQ40, VQ41 y VQ44) y en las bardas intermedias cercanas a su desembocadura (actual sitio VQ23; fig. 2). Los motivos descriptos incluyen negativos de manos de 


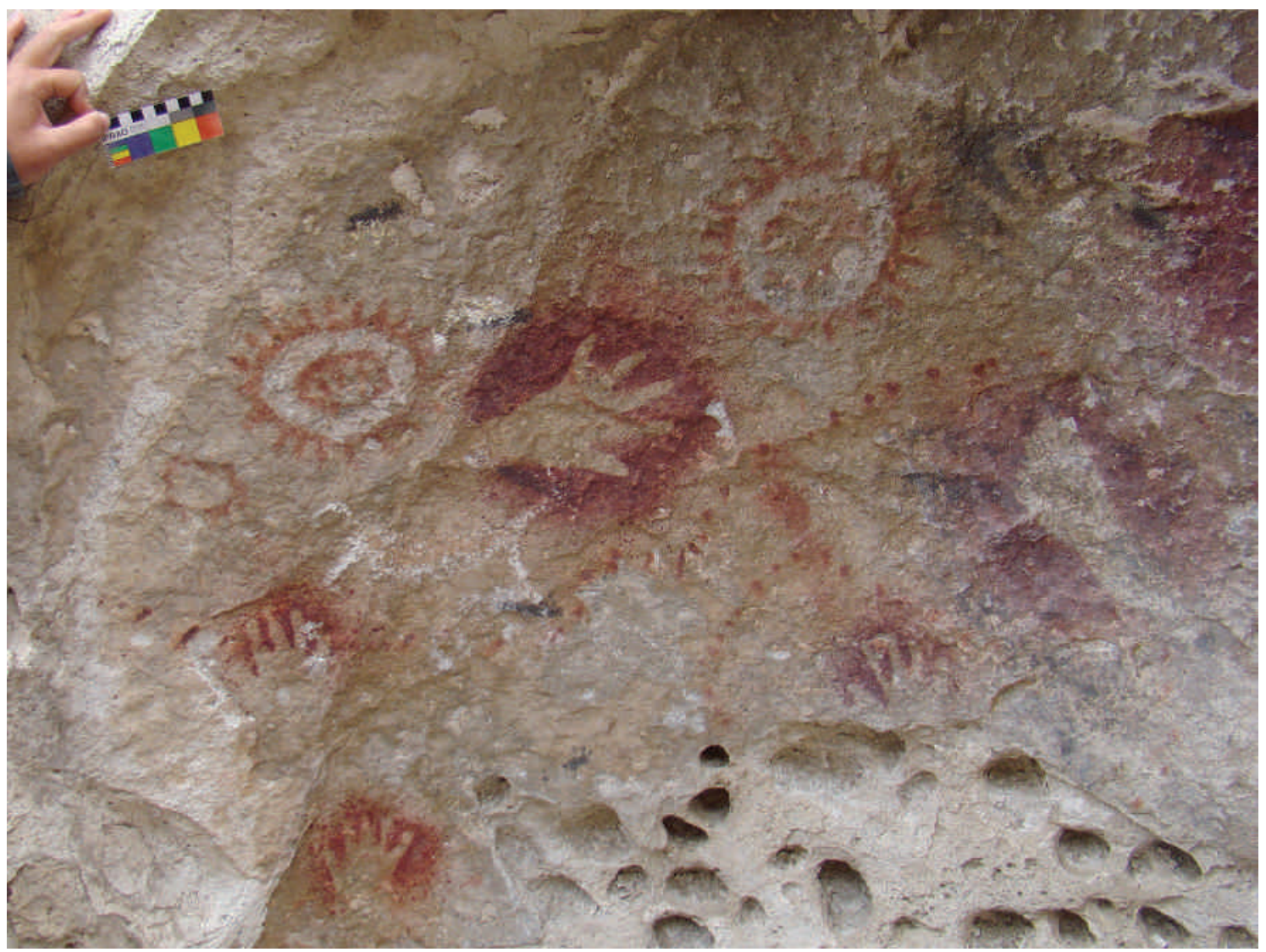

Figura 3. Panel con motivos característicos del grupo B.1 (sitio VQ21). Figure 3. Panel with group B.1 motifs (site VQ21).

varios colores, rayas escalonadas, guanacos y animales esquematizados -de color rojo y negro- que interpretó como representaciones de fauna extinta, por ejemplo: "dromedario", "caballo patagónico (onohippidium)", "cérvido", "auquénido", "marsupial o tripotérido", "gliptodóntido" e "hipopótamo-toxodóntido" (Molina 1972: 29).

Posteriormente, Gradin \& Aguerre (1983) identificaron y registraron 12 nuevos sitios con arte, pertenecientes a los sectores de bardas altas e intermedias que no habían sido descriptos por Molina (1972) (fig. 2). A partir del análisis morfológico de los motivos registrados, los autores clasificaron el arte rupestre de Viuda Quenzana en dos grupos estilísticos semejantes a los del Área Río Pinturas:

a) el grupo B.1, conformado por conjuntos de negativos de mano, biomorfos (estilizados y esquematizados), negativos de pie, de pata de choique y motivos puntiformes circulares y rectilíneos (fig. 3), realizados en tres series tonales diferentes ("roja-roja violácea", "negra" y "blanca policroma"; Gradin \& Aguerre 1983: 217);

b) el grupo $\mathrm{D}$, representado por escasos motivos curvilíneos grabados (Gradin \& Aguerre 1983).

Dada la ausencia en la localidad de excavaciones que permitieran ubicar temporalmente estos grupos estilísticos, Gradin \& Aguerre (1983) utilizaron información estratigráfica proveniente del sitio Cueva 4 de La Martita (ca. $25 \mathrm{~km}$ al norte de Viuda Quenzana). De este modo, vincularon el grupo B.1 con las ocupaciones "Casapedrenses" del sitio, datadas en ca. 4500 años AP y el grupo D con las ocupaciones "Patagonienses" datadas ca. 1700 años AP (Gradin \& Aguerre 1983: 222). Excavaciones posteriores, llevadas a cabo por Franco y equipo, en dos de los sitios identificados por Gradin \& Aguerre (VQ7 y VQ8), arrojaron fechados correspondientes al Holoceno medio para VQ8 $(4770 \pm 25$ y $4740 \pm 25$ años AP; 
Franco et al. 2013) y al Holoceno tardío para VQ7 (1220 \pm 20 años AP; Franco et al. 2015). Estas dataciones son consistentes con las estimaciones temporales realizadas por los investigadores antecedentes.

Finalmente, en 2001, Gradin utilizó algunas siluetas de guancos que registró en localidad como ejemplos gráficos de manifestaciones del grupo B del Área Río Pinturas en la Meseta Central de Santa Cruz (Gradin 2001; fig. 5: motivo 9 b, c y e, pp. 851). De acuerdo con trabajos previos del autor, el grupo estilístico B se ubicaría temporalmente en torno a los ca. 7300 años AP, al menos para el Área Río Pinturas (Gradin et al. 1976, 1979).

En función de lo expuesto es posible inferir la existencia de dos tipos de objetivos diferentes en las investigaciones previas sobre el arte rupestre de Viuda Quenzana. El primer tipo incluye, en el caso de Molina (1972), objetivos descriptivos y empíricos, con escasas preguntas previas explícitas y algunas inferencias infundadas respecto de los referentes representados en algunos motivos, particularmente en el caso de los taxa asignados a los motivos zoomorfos. El segundo tipo incluye, en el caso de Gradin y Aguerre (1983), objetivos cronológicos-estilísticos, orientados hacia la clasificación morfológica de los motivos registrados en la localidad y su ordenamiento geográfico y temporal utilizando indicadores provenientes de secuencias regionales de producción rupestre (área Río Pinturas) y de excavaciones de localidades vecinas (La Martita).

Pese a las diferencias de objetivos, ambas investigaciones comparten puntos en común: a) el trabajo sobre una muestra parcial del total de sitios rupestres presentes en la localidad; b) la focalización sobre los motivos que consideraron más importantes dentro del arte rupestre de la localidad, de acuerdo con sus objetivos. Así, generaron aportes fundamentales para el desarrollo de la arqueología de dicha localidad. Frente a este panorama surgió la necesidad de re-caracterizar la variabilidad rupestre observada en Viuda Quenzana mediante un análisis integral de la información proveniente de los sitios ubicados en distintos sectores de la localidad (que hasta el momento habían sido tratados por separado en las investigaciones previas), la inclusión de nuevos sitios en cada sector, y el registro de nuevos motivos identificados en relevamientos recientes (Franco et al. 2013, Acevedo 2017).

\section{MARCO TEÓRICO}

El marco teórico sobre el cual se basa el presente trabajo concibe al arte rupestre como un producto de cultura material. La materialidad del arte está centrada tanto en el hecho de que las imágenes son productos físicos generados a través del trabajo humano mediante la manipulación y transformación de materias primas a través de técnicas y artefactos, como en el hecho de que las características materiales de dichas imágenes tienen improntas de la agencia de quienes las produjeron inicialmente (Aschero 1988, Gell 1998, Fiore 2011). Estas características, a su vez, ejercieron efectos concretos sobre las personas que interactuaron con dichas imágenes a lo largo del tiempo, influyendo sobre la reutilización (o no) de soportes rocosos, manteniendo y/o reciclando las imágenes originales o superponiendo sobre éstas otras nuevas (Aschero 1997, Gell 1998, Fiore 2011).

Dentro de los múltiples factores que caracterizan la materialidad del arte rupestre, en este trabajo nos orientaremos a analizar cuatro: emplazamiento espacial, motivos, tipos de motivos y técnicas de ejecución. Una de las cualidades materiales específicas del arte rupestre es su espacialidad, en tanto que, por definición, se trata de imágenes plasmadas en un soporte rocoso inmóvil. Esto le otorga al arte rupestre una altísima resolución espacial, que permite evaluar la intencionalidad de quienes emplazaron los motivos en cuanto a los procesos de selección de soportes y composición de las imágenes. En este trabajo nos concentraremos en analizar los tipos de topografía de los sitios seleccionados para plasmar las imágenes, la frecuencia total de producción de motivos rupestres en cada sitio y la recurrencia y variabilidad de los repertorios de tipos de motivos identificados en distintos sectores de la localidad. Sumada a su cualidad espacial, la cualidad visual del arte permite marcar el espacio a partir de la transformación del soporte rocoso mediante tecnologías artísticas: en este caso presentaremos sintéticamente tanto las técnicas de producción utilizadas para crear las imágenes (ej. distintos tipos de pintura y/o distintos tipos de grabado), como las técnicas gráficas empleadas en el diseño de los motivos (que incluyen el tratamiento gráfico de la morfología del motivo y modo de aplicación del trazo con el cual ha sido producido el motivo; ver Metodología).

En trabajos anteriores sobre otras regiones hemos ya señalado que un primer análisis del arte rupestre que permita caracterizar las dinámicas de producción 
artística a escala de localidad, puede tomar en conjunto la totalidad de motivos hallados en los sitios bajo estudio sin discriminar posibles eventos distintos de ejecución (Acevedo et al. 2012-2014). Esto implica que, tanto en lo relativo a la frecuencia de motivos, como a la recurrencia y variabilidad de los repertorios de tipos de motivos, se estará analizando la inversión laboral de producción artística acumulada a lo largo del tiempo (Fiore \& Acevedo 2016). Este análisis, a su vez, se efectúa a partir del conjunto de motivos registrados en el presente, que ha perdurado más allá de los efectos del deterioro generados por procesos naturales y antrópicos que afectaron a la conservación de las imágenes, por lo cual obviamente no puede considerárselo como representativo de la sumatoria total de la producción artística de la localidad (Rosenfeld 1988, Bednarik 2001, Fiore 2006). Por lo tanto, las recurrencias y la variabilidad en el uso de determinados motivos del repertorio rupestre que puedan ser inferidas a través de los análisis propuestos deben evaluarse como resultados generales que potencialmente integran numerosos eventos discretos de producción y de posible reutilización de las imágenes.

Interesantemente, la evaluación del vínculo entre recurrencias y variabilidad en el repertorio rupestre requiere necesariamente una escala espacial amplia (que exceda la escala del sitio), tal como es el caso de la localidad Viuda Quenzana, debido a que, para evaluar el comportamiento similar o diferencial de los repertorios, se requiere poder comparar entre varios sitios distintos para obtener tendencias significativas. Así, los resultados obtenidos permiten arrojar luz sobre la historia de ocupación humana de dicha localidad, en tanto que posibilitan conocer si, a lo largo del tiempo -de manera acumulativa-, dichas poblaciones pusieron más énfasis en producir más motivos de los mismos tipos -generando tendencias hacia la recurrencia- o en producir más tipos de motivos distintos - generando tendencias hacia la variabilidad-. En tal sentido, visto desde un modelo esquemático de situaciones posibles, la evaluación combinada de $\mathrm{N}$ de motivos y $\mathrm{N}$ de tipos de motivos en los sitios arqueológicos que integran una localidad puede generar cuatro situaciones diferenciales:

I) bajo $\mathrm{N}$ de motivos y alto $\mathrm{N}$ de tipos de motivos: indica una tendencia hacia la variabilidad por sobre la recurrencia de tipos de motivos, lo cual implica un énfasis en la creación de distintos tipos de motivos por sobre la producción neta de ellos en cuanto tales. A su vez, esto sugiere la existencia de situaciones socioculturales, de comunicación de información, estéticas y simbólicas que, o bien han variado a lo largo del tiempo, o bien incluso si no han variado, han privilegiado comparativamente la creatividad y la libertad de expresión por sobre la consistencia informativa y/o expresiva mediada por la estandarización.

II) alto $\mathrm{N}$ de motivos y bajo $\mathrm{N}$ de tipos de motivos: indica una tendencia hacia la recurrencia por sobre la variabilidad de tipos de motivos, lo cual implica un énfasis en la repetición de los mismos tipos de motivos ya conocidos a lo largo de los distintos eventos de su producción. A su vez, esto sugiere la existencia de situaciones socioculturales, de comunicación de información, estéticas y/o simbólicas que no parecen haber variado mucho a lo largo del tiempo, reproduciéndose diacrónicamente de manera efectiva y que han privilegiado comparativamente la consistencia informativa y/o simbólica mediada por la estandarización para lograr comunicar información y/o contenidos simbólicos eficientemente. Esta situación es consistente con la existencia de una ideología cuya expresión material mediante imágenes visuales habría buscado reproducirla sin amplios márgenes de variación para mantener consistente la efectividad de su discurso.

III) alto $\mathrm{N}$ de motivos $\mathrm{y}$ alto $\mathrm{N}$ de tipos de motivos: indica una situación de equilibrio entre la producción de motivos y la producción de tipos de motivos, lo cual implica que, a nivel comparativo inter-sitio, cuando aumenta el $\mathrm{N}$ de una de las variables aumenta el $\mathrm{N}$ de la otra variable. Esto supone una situación dependiente del tamaño de la muestra, en la cual no es posible asegurar que la mayor variabilidad de tipos de motivos no sea un subproducto de la mayor cantidad producida, generándose así un sesgo dependiente de la frecuencia de casos, que no provee información estadísticamente significativa que nos permita distinguir intencionalidad de producir más o menos variabilidad de tipos de motivos.

IV) bajo $\mathrm{N}$ de motivos y bajo $\mathrm{N}$ de tipos de motivos: indica una situación de equilibrio entre la producción de motivos y la producción de tipos de motivos igual que en el caso III, pero con baja frecuencia en ambas variables.

En la realidad es esperable que se registren situaciones más moderadas que las presentadas en el modelo. Estos 
cuatro casos del modelo sirven como parámetro para orientar la búsqueda e interpretación de tendencias en los sitios bajo estudio. En el siguiente acápite se presentan los métodos de registro y procesamiento de datos para operacionalizar y evaluar cada una de las variables mencionadas en este acápite.

\section{METODOLOGÍA}

Para dar cuenta del emplazamiento del arte rupestre y la frecuencia de motivos, tipos de motivos y técnicas de ejecución presentes en la muestra, se utilizó una metodología de registro y análisis a tres escalas: sitio, panel y motivo. En función de los objetivos planteados inicialmente la escala de panel no será abordada en este trabajo, sino que el mismo se concentrará en las escalas de sitio y motivo. De esta manera, el sitio rupestre será la máxima escala de registro y análisis de datos y la definición aquí adoptada es la de: una concentración espacial discreta de motivos rupestres en el interior de soportes rocosos con límites precisables a partir de su morfología (e.g. alero, cueva, paredón) (Hernández Llosas 1985, Re 2010, Fiore \& Acevedo 2017). Por su parte, el motivo será la unidad mínima de registro y análisis y la definición aquí adoptada es la de: una expresión gráfica resultante de la utilización de uno o varios elementos decorativos básicos -empleados de manera única, reiterada y/o combinada-, ejecutada mediante un elemento único de trazo unitario y/o mediante elementos discretos con una proximidad espacial notoria entre sí que se unen para formar una sola entidad visual mayor (Gradin 1978, Hernández Llosas 1985, Aschero 1988, Fiore 2002).

Una vez definidas las escalas de trabajo el desarrollo de la metodología se organizó en tres etapas: 1) definición de variables, diseño de planilla de registro y base de datos y relevamiento de campo; 2) carga de información en la base de datos; y 3 ) análisis de datos (Fiore 2009, 2016; Fiore \& Acevedo 2016; Acevedo 2017).

El registro en el campo se realizó mediante fotografías y planillas de relevamiento diseñadas para recoger datos sobre el arte rupestre de la localidad a escala de sitio, panel y motivo (Hernández Llosas 1985, 2009; Fiore 2009, 2016; Fiore \& Acevedo 2016). El llenado de planillas se efectuó siguiendo un protocolo que define las variables a relevar y sus estados posibles, sistematizando, de esta manera, la recolección de información y reduciendo el margen de error asociado al investigador (Fiore 2009, 2016). Acorde con este protocolo se registró información sobre un total de 26 variables a escala de sitio y 26 variables a escala de motivo (Acevedo 2017), de las cuales se analizarán aquí las consideradas pertinentes a los objetivos del trabajo: a) a escala de sitio: sector de la localidad en que se ubica, número, nombre, punto GPS, materia prima del soporte rocoso, tipo de topografía del soporte rocoso (e.g. alero cueva, paredón o bloque), orientación cardinal (e.g. norte, sur, este, oeste, etc.), frecuencia de paneles con arte, ancho de boca, profundidad y altura;

b) a escala de motivo: número de motivo, nombre del tipo de motivo, ${ }^{2}$ técnica de producción, tratamiento gráfico de la morfología (lineal, perimetral, areal) y modo de aplicación del trazo (continuo y/o discontinuo).

Una vez finalizados los relevamientos de campo las fotografías capturadas fueron procesadas con el software DStretch-ImageJ (Harman 2008). Toda la información generada en el campo y laboratorio se volcó en una base de datos de múltiples escalas (Fiore 2009). Esta incluye dos tablas (por sitio y por motivo) vinculadas entre sí por el número de sitio. En la etapa de procesamiento de datos, se realizaron análisis estadísticos univariados y bivariados, a diferentes escalas y entre escalas para efectuar la caracterización morfológica, técnica y de emplazamiento de los motivos. Adicionalmente, para evaluar la variabilidad de los repertorios de tipos de motivos por sitio, se calculó el índice NTM/NM ( $\mathrm{N}$ de tipos de motivos dividido por $\mathrm{N}$ de motivos), que ya fuera empleado con anterioridad (Fiore \& Acevedo 2016). Este índice promedia la frecuencia total de $\mathrm{TM}$ respecto del $\mathrm{N}$ de motivos en un sitio, logrando un resultado entre $0, \mathrm{x} \mathrm{y} 1$ : a) resultados cercanos a 0 indican la presencia de pocos $\mathrm{TM}$ en relación con el $\mathrm{N}$ de motivos registrados, es decir, baja variabilidad en el repertorio;

b) resultados cercanos a 1 indican la presencia de mayor cantidad de TM en relación con el $\mathrm{N}$ de motivos registrados, es decir, mayor variabilidad en el repertorio. Por ejemplo, un resultado igual a 1 significa que a cada motivo registrado le corresponde TM diferente, lo que implica la máxima variabilidad posible, mientras que un resultado cercano a $0, x$ significa que hay pocos TM repartidos entre los motivos registrados en el sitio (Fiore \& Acevedo 2016). ${ }^{3}$ Así, su cálculo permite evaluar comparativamente la variabilidad en la producción rupestre entre sitios ponderando las frecuencias de TM presentes en cada sitio respecto de su $\mathrm{N}$ total de motivos. 


\section{RESULTADOS A ESCALA DE SITIO}

Los relevamientos sistemáticos realizados en Viuda Quenzana permitieron relocalizar 18 sitios que habían sido previamente registrados por otros autores (Molina: $\mathrm{n}=5$; Gradin \& Aguerre: $\mathrm{n}=14$; tabla 1$)^{4}$ e identificar 26 nuevos sitios, completando un total de 44 sitios con arte en la localidad: 8 en Bardas Altas, 18 en Bardas Intermedias y 18 en Cañadón Bajo. En términos generales, la producción rupestre de la localidad es principalmente pintada con escasos motivos grabados $(n=5)^{5}$ y picto-grabados $(n=5)$ concentrados en solo dos sitios de la localidad (VQ21 y VQ23), en asociación con motivos pintados.

Tabla 1. Equivalencias entre la denominación actual de los sitios y denominaciones previas por parte de otros investigadores. Table 1. Current site names and earlier site names.

DENOMINACIÓN DE LOS SITIOS CON ARTE RUPESTRE

\begin{tabular}{|c|c|c|}
\hline Actual & Gradin \& Aguerre 1983 & Molina 1972 \\
\hline VQ1 & Quenzana 1 & - \\
\hline VQ2 & Quenzana 2 (sector B) & - \\
\hline VQ3 & Quenzana 2 (sector A) & - \\
\hline VQ4 & Quenzana 3 (sector A) & - \\
\hline VQ5 & Quenzana 3 (sector B) & - \\
\hline VQ6 & Quenzana 3 (sector C) & - \\
\hline VQ21 & Quenzana 4 & - \\
\hline VQ22 & Quenzana 5 & - \\
\hline VQ7 & Quenzana 7 & - \\
\hline VQ8 & Quenzana 8 & - \\
\hline VQ23 & Quenzana 9 & Mencionado \\
\hline VQ24 & Quenzana 10 & - \\
\hline VQ25 & Quenzana 11 & - \\
\hline VQ26 & Quenzana 12 & - \\
\hline VQ34 & - & Mencionado \\
\hline VQ40 & - & Mencionado \\
\hline VQ41 & - & Mencionado \\
\hline VQ44 & - & Mencionado \\
\hline
\end{tabular}

\section{Caracterización general de los sitios con arte en el sector Bardas Altas}

En el sector de Bardas Altas (en adelante BA) se registró un total de 8 sitios con arte (tabla 2), la mayoría de ellos emplazados en aleros $(n=7)$, con excepción de un único sitio localizado en una cueva (tabla 2). En todos los casos, se trata de sitios de fácil acceso, orientados en dirección general hacia el norte $(\mathrm{N}: \mathrm{n}=5$; NE: $\mathrm{n}=1$; NW: $n=1$; y NE: $n=1$ ), con superficies generales cóncavas y topografías internas accidentadas (e.g. presencia de fisuras, grietas, nichos, reparos y salientes) (tabla 2). Las principales diferencias entre los sitios de BA, más allá de lo morfológico, están dadas por sus tamaños, que incluyen: a) sitios altos y profundos, de grandes dimensiones $(\mathrm{n}=3)$; b) sitios bajos y poco profundos, de medianas dimensiones $(\mathrm{n}=2)$; $\mathrm{y} \mathrm{c}$ ) sitios pocos profundos, con escaso reparo, de pequeñas dimensiones $(\mathrm{n}=3)$ (tabla 2). Por su posición elevada en el terreno todos los sitios del sector presentan buenas condiciones de visibilidad de sus alrededores.

En los 8 sitios relevados, se registró la presencia de 353 motivos distribuidos en 50 paneles, desde un sitio con solo un panel y tres motivos (e.g. VQ6), hasta un sitio con 14 paneles y 163 motivos (e.g. VQ21). En términos generales, los sitios de grandes dimensiones (e.g. VQ1, VQ2, VQ21) poseen más paneles con arte y más motivos que el resto de los sitios (tabla 2).

Para finalizar, el estado de conservación del arte de BA oscila entre regular y malo. Esto se debe a los elevados niveles de obliteración de las pinturas y, fundamentalmente, los bajos grados de integridad morfológica de los motivos registrados como consecuencia de la exfoliación y remoción natural del soporte rocoso generada por el accionar de la erosión catafilar sobre las ignimbritas de bajo grado de compactación, altamente friables (fig. 4). La presencia de manchas de pintura en todos los sitios del sector es un indicador fehaciente del deterioro de los motivos rupestres. En un sitio del sector (VQ21) se registró la presencia de intervención antrópica reciente mediante la realización de grafitis pintados con pintura sintética (fig. 4). 
Tabla 2. Caracterización general de los sitios con arte en BA. Table 2. Main features of rock art sites in BA.

\begin{tabular}{c|c|c|c|c|c|c|c|c|c} 
SITIO & MORFOLOGIA & ORIENTACIÓN & $\begin{array}{c}\text { ANCHO } \\
\text { BOCA }\end{array}$ & $\begin{array}{c}\text { ALT. MAX. } \\
(\mathrm{m})\end{array}$ & $\begin{array}{c}\text { PROF. MAX. } \\
(\mathrm{m})\end{array}$ & TAMAÑO & $\begin{array}{c}\text { NTM } \\
\text { (No de paneles } \\
\text { con arte })\end{array}$ & $\begin{array}{c}\text { NM } \\
\left(N^{\circ} \text { de }\right. \\
\text { motivos })\end{array}$ & $\begin{array}{c}\text { NTM } \\
\left(\mathbf{N}^{\circ} \text { de tipos }\right. \\
\text { de motivos })\end{array}$ \\
\hline VQ2 & Alero & Norte & 16,8 & 6 & 8,7 & Grande & 16 & 72 & 11 \\
\hline VQ3 & Cueva & Noreste & 4 & 3 & 4,3 & Mediano & 3 & 40 & 6 \\
\hline VQ4 & Alero & Norte & 4,3 & 1,5 & 1,45 & Pequeño & 2 & 14 & 9 \\
\hline VQ5 & Alero & Norte & 5,3 & 2,5 & 2,3 & Pequeño & 3 & 13 & 2 \\
\hline VQ6 & Alero & Norte & 5,1 & 4 & 2,2 & Pequeño & 1 & 3 & 2 \\
\hline VQ21 & Alero & Norte & 18,4 & 6 & 9,8 & Grande & 14 & 163 & 37 \\
\hline VQ22 & Alero & Noreste & 10 & 2,9 & 2,9 & Mediano & 5 & 16 & 7
\end{tabular}
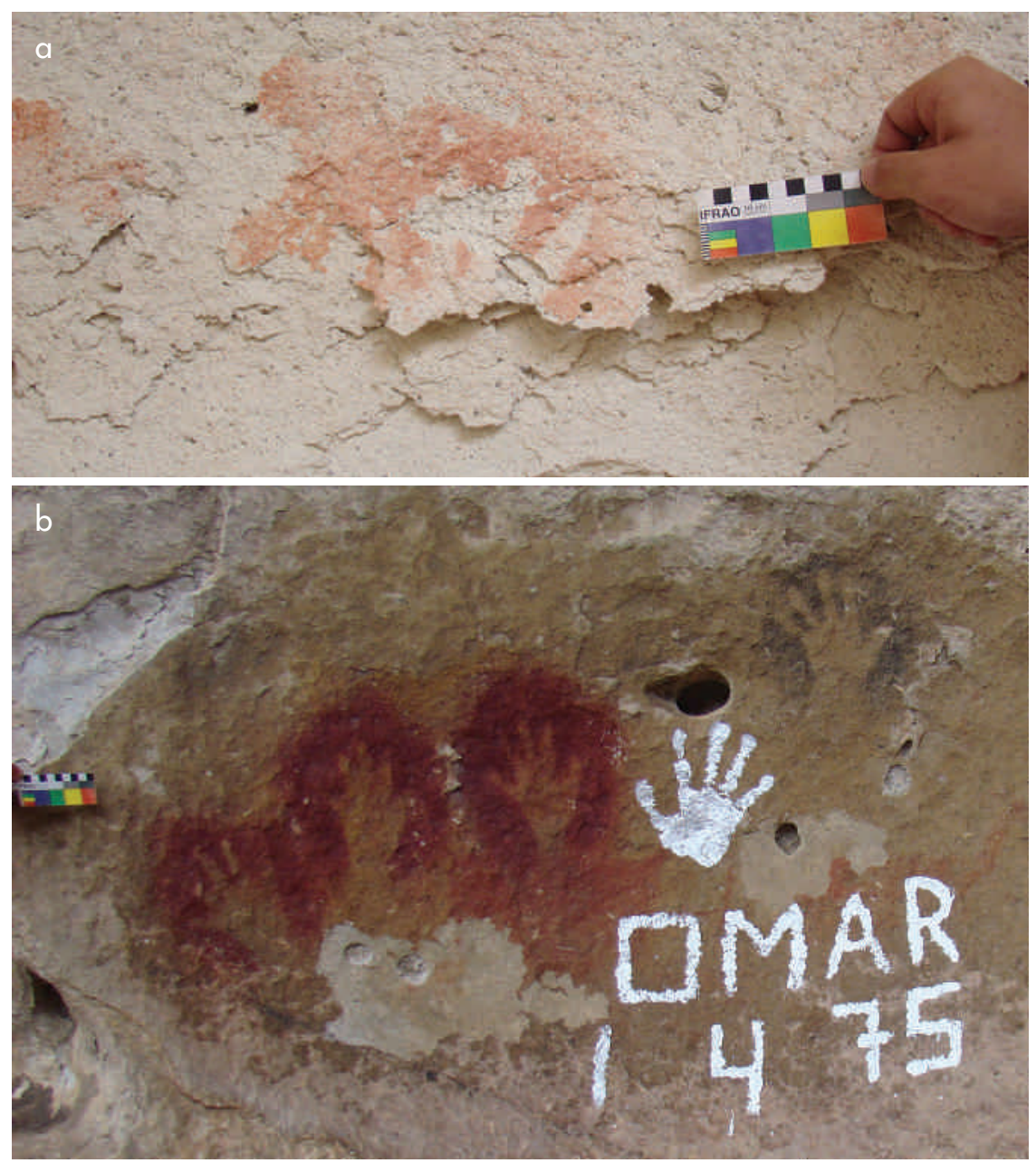

Figura 4. Estado de conservación de los motivos rupestres en BA: a) motivos afectados por erosión catafilar de la roca soporte (sitio VQ2); b) motivos afectados por acción antrópica reciente (sitio VQ21).

Figure 4. Conservation state of rock art motifs in BA: a) motifs affected by cataphyllary erosion of the support rock (site VQ2); b) motifs affected by recent anthropic action (site VQ21). 
Tabla 3. Caracterización general de los sitios con arte rupestre en BI. Table 3. Main features of rock art sites in BI.

\begin{tabular}{|c|c|c|c|c|c|c|c|c|c|}
\hline SITIO & MORFOLOGÍA & ORIENTACIÓN & $\begin{array}{c}\text { ANCHO } \\
\text { BOCA }\end{array}$ & $\begin{array}{l}\text { ALT. MAX. } \\
\text { (m) }\end{array}$ & $\begin{array}{l}\text { PROF. MAX. } \\
\text { (m) }\end{array}$ & TAMAÑO & $\begin{array}{c}\text { NTM } \\
\left(\mathrm{N}^{\circ} \text { de paneles }\right. \\
\text { con arte })\end{array}$ & $\begin{array}{c}\text { NM } \\
\left(\mathrm{N}^{\circ} \text { de }\right. \\
\text { motivos })\end{array}$ & $\begin{array}{c}\text { NTM } \\
\left(\mathrm{N}^{\circ} \text { de tipos }\right. \\
\text { de motivos) }\end{array}$ \\
\hline VQ7 & Cueva & Noreste & 5,2 & 1,7 & 7,4 & M & 4 & 15 & 4 \\
\hline VQ8 & Alero & Norte & 12,2 & 1,4 & 2 & $\mathrm{P}$ & 6 & 45 & 11 \\
\hline VQ9 & Alero & Sur/Suroeste & 10 & 3 & 1,6 & M & 4 & 32 & 2 \\
\hline VQ10 & Alero & Suroeste & 4,6 & 3 & 3,1 & M & 1 & 27 & 8 \\
\hline VQ11 & Alero & Sur & 8 & 2 & 2,5 & $\mathrm{P}$ & 1 & 6 & 5 \\
\hline VQ12 & Paredón & Oeste/Suroeste & 4,5 & 2,2 & 1 & $\mathrm{P}$ & 1 & 8 & 4 \\
\hline VQ13 & Alero & Este/Noreste & 6,7 & 1,6 & 0,6 & $\mathrm{P}$ & 1 & 17 & 5 \\
\hline VQ14 & Alero & Sur/Sureste & 15,5 & 2 & 8,5 & $\mathrm{P}$ & 2 & 3 & 3 \\
\hline VQ15 & Alero & Sur & 12,5 & 4 & 5,1 & M & 9 & 61 & 12 \\
\hline VQ16 & Alero & Sur & 5,7 & 1,7 & 2,4 & $\mathrm{P}$ & 6 & 41 & 13 \\
\hline VQ17 & Alero & Sur/Oeste & 7,5 & 2,9 & 2,5 & $\mathrm{P}$ & 7 & 69 & 14 \\
\hline VQ18/20 & Alero & Oeste & 28,2 & 2,5 & 4,3 & M & 8 & 39 & 7 \\
\hline VQ19 & Alero & Sur/Suroeste & 11 & 2,3 & 1,3 & $\mathrm{P}$ & 2 & 10 & 2 \\
\hline VQ23 & Alero & Noreste & 13,9 & 3 & 2,5 & M & 21 & 363 & 24 \\
\hline VQ24 & Alero & Norte & 15 & 1,8 & 1,8 & $\mathrm{P}$ & 1 & 7 & 2 \\
\hline VQ25 & Alero & Norte & 9,3 & 1,9 & 1,8 & $\mathrm{P}$ & 1 & 3 & 1 \\
\hline VQ26 & Alero & Norte/Noreste & 3,3 & 2,1 & 1,7 & $\mathrm{P}$ & 2 & 3 & 2 \\
\hline VQ45 & Alero & Norte/Noroeste & 18,5 & 4 & 2,7 & M & 3 & 3 & 1 \\
\hline
\end{tabular}

\section{Caracterización general de los sitios con arte en el sector Bardas Intermedias}

En el sector de Bardas Intermedias (en adelante BI) se registró un total de 18 sitios con arte consistentes mayoritariamente en aleros $(n=16)$ y, en menor medida, en cuevas $(n=1)$ y paredones $(n=1)$ (tabla 3 ). Las orientaciones generales de los sitios registrados son variables (S: $n=8 ; N: n=7 ; W: n=2 ; y E: n=1$ ) (tabla 3). También son variables sus superficies generales, que incluyen sitios de superficie cóncava, plana, cóncavaplana, cóncava-convexas y cóncava-convexa-plana. Es interesante la ausencia de sitios grandes dentro del sector y el predominio de sitios pequeños, poco profundos con escaso reparo $(\mathrm{n}=11)$ y sitios medianos $(\mathrm{n}=7)$ (tabla 3$)$. Por su posicionamiento menos elevado en el terreno, su ubicación sobre diferentes planos de inclinación de una lomada y la presencia de múltiples afloramientos rocosos, la amplitud y longitud de visibilidad desde los sitios es variable, con casos de visibilidad amplia y larga de sus alrededores y casos de visibilidad corta y restringida. Se trata de sitios de fácil acceso y con topografías internas accidentadas (e.g. presencia de fisuras, grietas, nichos, salientes y en menor medida reparos).

En los 18 sitios de BI se registró la presencia de 752 motivos distribuidos en 80 paneles, incluyendo desde un sitio con solo un panel y tres motivos (e.g. VQ26), hasta un sitio con 21 paneles y 363 motivos (e.g. VQ23). Este último sitio es el que posee mayor cantidad de paneles y motivos de toda la localidad. A diferencia de lo que ocurre en BA, en BI no se aprecia una correlación entre el tamaño de los sitios (medianos y pequeños) y la cantidad de paneles y motivos, sino que la relación es variable (tabla 3 ). 
Respecto del estado de conservación del arte, ocurre algo similar a lo previamente señalado para el sector de BA: la preservación regular y mala de los motivos registrados, con baja integridad morfológica, producto de la remoción natural del sustrato rocoso debido al accionar de la erosión catafilar sobre las ignimbritas de bajo grado de compactación, compartidas entre ambos sectores. En dos sitios del sector (VQ22 y VQ23) se registró la presencia de intervención antrópica reciente mediante la extracción -e intento de extracción- de secciones de rocas con motivos.

\section{Caracterización general de los sitios con arte en el sector Cañadón Bajo}

En el sector de Cañadón Bajo (en adelante CB) se registraron 18 sitios con arte, ${ }^{5}$ consistentes principalmente en aleros $(\mathrm{n}=8)$, cuevas $(\mathrm{n}=8)$ y, en menor medida, paredones $(n=2)$ (tabla 4). Esto marca una diferencia con los sectores previamente descriptos, en los que prácticamente no se observa la utilización de cuevas (tabla 2-3). La mayoría de los sitios registrados están orientados hacia el norte $(\mathrm{n}=10)$, seguido por los emplazamientos orientados hacia el sur $(n=5)$ y, en menor medida, los direccionados hacia el este $(n=2)$ y oeste $(n=1)$ (tabla 4$)$. Al igual que en BI, se observa un predominio de sitios de pequeñas dimensiones ( $\mathrm{n}=11)$ y medianas dimensiones $(\mathrm{n}=6)$, con escaso aprovechamiento de sitios grandes $(\mathrm{n}=1)($ tabla 4$)$. En términos generales, se trata de sitios de fácil acceso, ${ }^{6}$ con topografías internas accidentadas (presencia de fisuras, grietas, nichos, salientes y reparos) y visibilidad corta y restringida de sus alrededores, producto de su localización en el interior del cañadón.

En los 18 sitios relevados se registraron 228 motivos distribuidos en 65 paneles, incluyendo sitios con un panel compuesto por un único motivo (e.g. VQ30 y VQ38), hasta un sitio con 17 paneles y 72 motivos (e.g. VQ44) (tabla 4). Nuevamente, al igual que en BI, no se observa la presencia de correlación entre el tamaño de los sitios y la cantidad de paneles y motivos, sino que la relación es variable (tabla 4).

A diferencia de los sectores de BA y BI, el estado de conservación del arte rupestre de $\mathrm{CB}$, en términos generales, es bueno. Esto se debe, fundamentalmente, a que las ignimbritas de alto grado de compactación del cañadón son menos friables que las ignimbritas de bajo grado de compactación de los sectores de bardas y, por lo tanto, más resistentes al accionar de la erosión catafilar, la cual no representa un agente determinante en el estado de preservación de las pinturas (Claudio Iglesias, comunicación personal 2014; fig. 5). Dentro de este sector se registró la presencia de intervención antrópica reciente en dos sitios (VQ41 y VQ42) mediante la realización de grafitis ejecutados con carbón (fig. 5).

\section{RESULTADOS A ESCALA DE MOTIVO}

La integración y comparación sistemática de la información obtenida para cada sector permite identificar interesantes tendencias. En primer lugar, la localidad suma un total de 1333 motivos: 353 en BA (en 8 sitios), 752 en BI (en 18 sitios) y 228 en CB (en 18 sitios; tabla 5). Esto permite generar una primera inferencia, relativa a que la producción de arte rupestre acumulada en el cañadón habría sido comparativamente menor que en las bardas, no dependiendo estrictamente de la cantidad de sitios donde se emplazaron las imágenes, ya que $\mathrm{BI}$, donde se registra la mayor cantidad de motivos, y CB, donde se registra la menor cantidad, tienen 18 sitios con arte cada uno. A su vez, los 1333 motivos se reparten en un total de $81 \mathrm{TM}$, lo cual indica que el repertorio fue considerablemente amplio, sugiriendo una alta variabilidad de diseños acumulada a lo largo del tiempo (tabla 5). La evaluación del NTM por sector indica que el sector con mayor variabilidad de TM es BI (NTM=51; $60 \%$ del repertorio); seguido por BA (NTM $=46 ; 56 \%$ del repertorio) y por $\mathrm{CB}(\mathrm{NTM}=38 ; 46 \%$ del repertorio). Estas proporciones son bastante consistentes con las frecuencias de motivos registradas en cada sector.

Ahora bien, una forma para evaluar cuestiones relativas a la comunicación visual efectiva en la localidad es la comparación de TM compartidos entre sectores. Los resultados demuestran que hay mayor similitud entre BA y BI (25 TM compartidos) y entre BI y CB (25 TM compartidos, tabla 6). Esto sugiere, en principio y como es esperable, que la comunicación visual habría sido levemente más fluida o directa entre sectores más próximos entre sí -BA con $\mathrm{BI}$ y $\mathrm{BI}$ con $\mathrm{CB}-$. A su vez, los tres sectores comparten un total de $17 \mathrm{TM}$. Visto comparativamente con el repertorio total, constituido por $81 \mathrm{TM}$, este NTM compartidos es bajo (21\% del repertorio). Los 17 TM compartidos entre los tres sectores son: manos negativas, manchas, guanacos, líneas sinuosas, líneas rectas, circunferencias, líneas curvas, arrastres de dedos individuales, áreas irregulares de 
Tabla 4. Caracterización general de los sitios con arte rupestre en CB. Table 4. Main features of rock art sites in CB.

\begin{tabular}{|c|c|c|c|c|c|c|c|c|c|}
\hline SITIO & MORFOLOGÍA & ORIENTACIÓN & $\begin{array}{c}\text { ANCHO } \\
\text { BOCA }\end{array}$ & $\begin{array}{l}\text { ALT. MAX. } \\
\text { (m) }\end{array}$ & $\begin{array}{l}\text { PROF. MAX. } \\
\text { (m) }\end{array}$ & TAMAÑO & $\begin{array}{c}\text { NTM } \\
\left(\mathrm{N}^{\circ} \text { de paneles }\right. \\
\text { con arte) }\end{array}$ & $\begin{array}{c}\text { NM } \\
\text { (No de } \\
\text { motivos) }\end{array}$ & 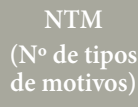 \\
\hline VQ27 & Alero & Sur/Este & 5,1 & 3,5 & 1,7 & $\mathrm{P}$ & 1 & 3 & 01 \\
\hline VQ28 & Alero & Este/Sureste & 2,7 & 2,1 & 2,3 & $\mathrm{P}$ & 6 & 14 & 2 \\
\hline VQ29 & Cueva & Sur & 2,2 & 2,4 & 2,4 & $\mathrm{P}$ & 1 & 3 & 2 \\
\hline VQ30 & Alero & Norte & 2,9 & 2,2 & 2,4 & $\mathrm{P}$ & 1 & 1 & 1 \\
\hline VQ31 & Paredón & Sur/Oeste & 7,4 & 7,5 & 2,5 & $\mathrm{P}$ & 1 & 5 & 1 \\
\hline VQ32 & Paredón & Sur/Suroeste & 2,3 & 3 & 1,1 & $\mathrm{P}$ & 1 & 11 & 1 \\
\hline VQ33 & Alero & Oeste & 4 & 1,8 & 3,7 & $\mathrm{P}$ & 3 & 40 & 19 \\
\hline VQ34 & Alero & Norte/Noroeste & 5 & 2,75 & 3 & $\mathrm{P}$ & 1 & 4 & 3 \\
\hline VQ35 & Alero & Norte/Noroeste & 4,4 & 3,2 & 3,75 & $\mathrm{P}$ & 3 & 5 & 2 \\
\hline VQ36 & Cueva & Este/Noreste & 2,8 & 3,5 & 7,2 & $\mathrm{P}$ & 1 & 2 & 2 \\
\hline VQ37 & Cueva & Norte/Noroeste & 3,6 & 2,6 & 7,4 & $\mathrm{M}$ & 2 & 2 & 1 \\
\hline VQ38 & Cueva & Norte/Noroeste & 7,3 & 2,6 & 12,4 & M & 1 & 1 & 1 \\
\hline VQ39 & Cueva & Norte & 9,3 & 2,8 & 10,6 & M & 8 & 15 & 2 \\
\hline VQ40 & Alero & Norte & 7,1 & 3 & 5,3 & M & 4 & 16 & 5 \\
\hline VQ41 & Cueva & Sur & 8,7 & 2,4 & 20 & G & 8 & 25 & 4 \\
\hline VQ42 & Cueva & Norte/Oeste & 6,4 & 4 & 10,4 & M & 4 & 6 & 4 \\
\hline VQ43 & Cueva & Norte/Este & 5,4 & 1,6 & 6,8 & $\mathrm{P}$ & 2 & 3 & 2 \\
\hline VQ44 & Alero & Norte/Noreste & 8,5 & 5 & 6,6 & M & 17 & 72 & 20 \\
\hline
\end{tabular}
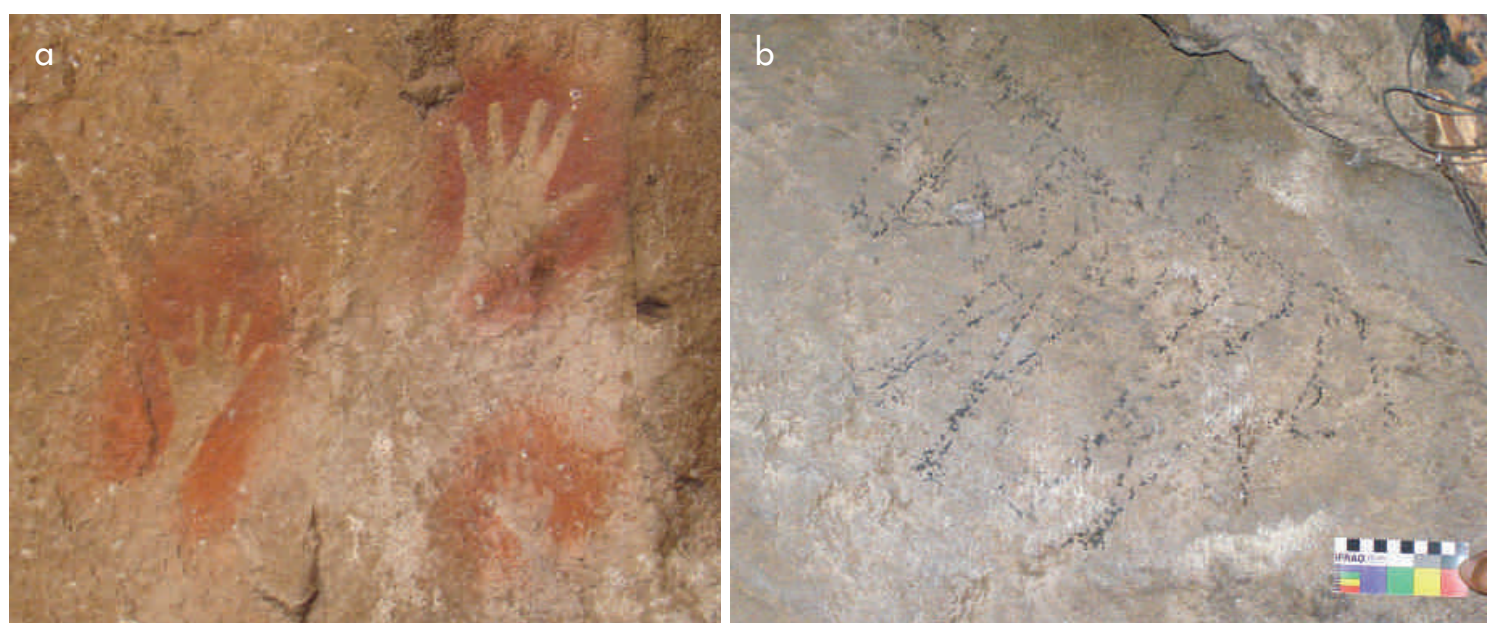

Figura 5. Estado de conservación de los motivos rupestres en CB. Referencias: a) baja afectación de la erosión catafilar sobre la roca soporte (sitio VQ40); b) grafiti reciente realizado con carbón (sitio VQ42). Figure 5. Conservation state of rock art motifs in CB. References: a) low impact of cataphyllary erosion on the support rock (site VQ40); b) recent graffiti made with charcoal (site VQ42). 
puntos, arrastres de dedos paralelos, líneas rectas paralelas múltiples, líneas en $U$, puntos agrupados, líneas sinuosas paralelas, óvalos, líneas rectas irregulares, puntos en par. Esto conduciría a sugerir que la comunicación visual entre sectores no habría sido altamente efectiva, ya que el porcentaje de motivos compartidos es relativamente bajo. Sin embargo, cuando se toman en cuenta las frecuencias de cada uno de estos TM compartidos, la cuestión toma otro cariz. Así, resulta ser que la suma de las frecuencias de casos -motivos reales- de cada uno de los 17 TM compartidos da un total de 1168 motivos. Esto implica que, si bien los 17 TM constituyen solo el 21\% del repertorio, cada uno de estos TM ha sido repetido con tanta frecuencia que los motivos rupestres creados usando esos diseños abarcan un $87,6 \%$ de la producción rupestre de la localidad. Más aún, dentro de esos 1168 motivos, los dos TM más frecuentes (exceptuando las manchas, de morfología indeterminable) son manos negativas $(\mathrm{n}=604)$ y guanacos $(\mathrm{n}=89)$. Esta información permite sugerir que, si bien la variabilidad del repertorio medida según el $\mathrm{N}$ total de TM es alta, la recurrencia en la selección de algunos TM en particular, para ser repetidos numerosas veces a lo largo de la producción de más motivos, ha generado una cierta estandarización en el corpus visual de las imágenes rupestres de la localidad. Ello permite sugerir que habría existido alguna forma de comunicación visual efectiva en y entre los sectores que componen la localidad. Así, la producción de nuevos motivos, pero repitiendo los mismos TM, habría facilitado la construcción de importantes tendencias recurrentes, visibles e interpretables dentro de un contexto visual más amplio, generado por el repertorio total.

Por otra parte, dentro del repertorio total hay también TM no compartidos por los tres sectores de la localidad, que sin embargo son significativos en cuanto a su capacidad representativa figurativa, que permite la identificación de referentes externos representados. Entre ellos, se encuentran las manos positivas, los tridígitos y las pisadas de felino, compartidos entre BI y CB; las pisadas negativas humanas y las pisadas negativas de choique, compartidos entre BA y BI (tabla 5). Interesantemente, todos estos elementos del repertorio remiten a huellas -en el sentido amplio-, tanto humanas como animales. Ello remite a la importancia, ya señalada por otros autores, acerca de la práctica del rastreo de presas y de animales peligrosos por parte de los cazadores-recolectores (Mithen 1988; Morphy 1989; Gradin 2001). En el caso de las manos positivas, éstas se suman a los casos más frecuentes -la producción de manos negativas- que caracterizan a la región. En conjunto, manos negativas y positivas han sido interpretadas en distintas regiones como formas de apropiación simbólica del espacio (Gradin et al. 1976, 1979; Gradin 2001; Aschero 2000; Carden 2009) y de construcción de un registro visual del vínculo entre personas y lugares (Ouzman 1998).

En ambos casos, el propio proceso de tocar y marcar espacios con las palmas de las manos, sea con pintura negativa o positiva, habría formado parte de una práctica de transformación de dichos espacios en lugares, haciendo visible su sentido previamente invisible y/o construyendo un nuevo sentido a partir de su marcación visual (Ouzman 1998). A su vez, el hecho de que a) las manos negativas y positivas incluyen distintos tamaños, desde adultos hasta bebés y b) están emplazadas en soportes de alta visibilidad y fácil accesibilidad, implican una participación de índole grupal en su producción y visualización, sin aparentes segregaciones intra-grupo por edad (Aschero 1997).

También se destaca una variedad de 28 TM construidos con elementos puntiformes, que suman un total de 111 motivos que corresponden a la clase de los geométricos simples en su mayoría: líneas sinuosas, líneas curvas y líneas rectas circunferencias, áreas irregulares de puntos y puntos agrupados, entre otros (tabla 5).

Además, son destacables por sus cualidades de diseño geométrico complejo las figuras ortogonales $(\mathrm{n}=8)$, los almenados $(\mathrm{n}=1)$ e incluso los zig-zag $(\mathrm{n}=6)$, siendo los dos primeros TM los ejemplos más diagnósticos de diseños producidos en momentos recientes de la secuencia regional del arte rupestre de Patagonia (ver en la página siguiente).

Ahora bien, tal como habíamos planteado en el marco teórico, el análisis del vínculo entre NTM y NM permite evaluar las tendencias hacia la variabilidad en la producción de TM (que implica mayor diversidad y amplitud social en la producción de diseños) versus las tendencias hacia la recurrencia en la repetición de TM (que implica menor diversidad y mayor control social en la producción de diseños). Los análisis efectuados permiten identificar casos ubicables en las distintas situaciones planteadas por el modelo. Así, el sitio VQ11 es asignable a la situación (I), de un bajo $\mathrm{N}$ de motivos $\mathrm{y}$ un alto NTM, ya que allí se registran solo 6 motivos, pero 5 TM distintos: en este sitio, la importante variabilidad de diseños registrada no parece responder a un efecto del bajo tamaño de la muestra (fig. 7). 
Tabla 5. Frecuencias de tipos de motivos, número de motivos y número de tipos de motivos por sector y en la localidad. Table 5. Frequencies of motif types (MT), N of motifs (NM) and NMT per sector and in the locality.

\begin{tabular}{|c|c|c|c|c|}
\hline TIPOS DE MOTIVOS & $\mathrm{BA}$ & BI & $\mathrm{CB}$ & TOTAL \\
\hline Almenado & - & 1 & - & 1 \\
\hline Antropomorfo & - & 1 & 1 & 2 \\
\hline Área irregular de puntos & 3 & 7 & 1 & 11 \\
\hline Arrastre de instrumento puntual & 4 & - & - & 4 \\
\hline Circunferencias adosadas & - & - & 1 & 1 \\
\hline Círculo & 2 & 1 & - & 3 \\
\hline Círculo con apéndice & 3 & - & - & 3 \\
\hline Círculo medio & 1 & - & - & 1 \\
\hline Círculos adosados & 1 & - & - & 1 \\
\hline Círculos concéntricos & 1 & - & - & 1 \\
\hline Circunferencia & 12 & 12 & 8 & 32 \\
\hline Circunferencia con apéndice & 1 & - & - & 1 \\
\hline Circunferencias concéntricas & 7 & - & 1 & 8 \\
\hline Circunferencias concéntricas con apéndice & 1 & - & - & 1 \\
\hline Circunferencias concéntricas radiadas & 2 & - & - & 2 \\
\hline Cruz & 1 & - & - & 1 \\
\hline Escaleriforme & - & 2 & 1 & 3 \\
\hline Espiral & - & 1 & - & 1 \\
\hline Figura ortogonal quebrada simple con línea quebrada & - & 1 & - & 1 \\
\hline Figura ortogonal quebrada simple con línea recta & - & 1 & - & 1 \\
\hline Figura ortogonal rectilínea compleja & - & 1 & - & 1 \\
\hline Figura ortogonal rectilínea simple & - & 2 & - & 2 \\
\hline Figura ortogonal rectilínea simple con línea quebrada & - & 1 & - & 1 \\
\hline Figura ortogonal rectilínea simple con líneas rectas & - & 1 & - & 1 \\
\hline Figura sinuosa & - & 1 & 2 & 3 \\
\hline Figura sinuosa adosada a figura ortogonal rectilínea simple & - & 1 & - & 1 \\
\hline Figuras sinuosas adosadas & - & 1 & - & 1 \\
\hline Guanaco & 31 & 9 & 49 & 89 \\
\hline Línea curva & 14 & 10 & 7 & 31 \\
\hline Línea curva adosada a zigzag & - & 1 & - & 1 \\
\hline Línea curva con apéndice & - & - & 2 & 2 \\
\hline Línea curva con línea $\mathrm{T}$ invertida interior & - & 1 & - & 1 \\
\hline
\end{tabular}




\begin{tabular}{|c|c|c|c|c|}
\hline TIPOS DE MOTIVOS & BA & BI & $\mathrm{CB}$ & TOTAL \\
\hline Línea curva espiralada rellena con líneas curvas y línea recta exterior & - & - & 1 & 1 \\
\hline Línea curva rellena con circunferencia y guiones paralelos múltiples & - & - & 1 & 1 \\
\hline Línea curva rellena con líneas sinuosas & 1 & - & - & 1 \\
\hline Línea recta & 10 & 22 & 4 & 36 \\
\hline Línea recta y líneas sinuosas paralelas & - & - & 1 & 1 \\
\hline Línea sinuosa & 13 & 17 & 9 & 39 \\
\hline Línea U & 2 & 2 & 2 & 6 \\
\hline Línea U con línea recta interior & 2 & - & 1 & 3 \\
\hline Línea U irregular peiniforme & 1 & - & - & 1 \\
\hline Línea $\mathrm{U}$ radiada con guiones paralelos & 2 & - & - & 2 \\
\hline Línea U rectilínea & - & 1 & - & 1 \\
\hline Líneas curvas concéntricas & - & 2 & - & 2 \\
\hline Líneas curvas concéntricas múltiples & 2 & 2 & - & 4 \\
\hline Líneas curvas líneas rectas y líneas quebradas entrecruzadas irregularmente & - & - & 1 & 1 \\
\hline Líneas curvas y líneas rectas entrecruzadas irregularmente & 1 & - & 1 & 2 \\
\hline Línea recta con apéndices rectos perpendiculares sólidos y punteados alternados & - & - & 1 & 1 \\
\hline Líneas rectas convergentes en circunferencia & - & - & 1 & 1 \\
\hline Líneas rectas irregulares & 1 & 1 & 1 & 3 \\
\hline Líneas rectas paralelas & 1 & - & 3 & 4 \\
\hline Líneas rectas paralelas múltiples & 3 & 4 & 1 & 8 \\
\hline Líneas sinuosas paralelas & 2 & 1 & 1 & 4 \\
\hline Líneas U concéntricas & 4 & - & - & 4 \\
\hline Líneas U concéntricas con línea recta interior & 2 & - & - & 2 \\
\hline Mancha & 56 & 168 & 35 & 259 \\
\hline Mano dibujada & - & 1 & 1 & 2 \\
\hline Matuasto & - & 1 & - & 1 \\
\hline Meandro rectilíneo & 1 & - & - & 1 \\
\hline Meandro & 1 & 2 & - & 3 \\
\hline Negativo de mano & 133 & 419 & 52 & 604 \\
\hline Negativo de objeto indeterminado & 1 & 1 & - & 2 \\
\hline Negativo de pata de choique & 2 & 4 & - & 6 \\
\hline Negativo de pie & 2 & 4 & - & 6 \\
\hline Óvalo & 1 & 2 & 1 & 4 \\
\hline Óvalo relleno con líneas rectas y manchas & 1 & - & - & 1 \\
\hline
\end{tabular}




\begin{tabular}{|c|c|c|c|c|}
\hline TIPOS DE MOTIVOS & $\mathrm{BA}$ & BI & $\mathrm{CB}$ & TOTAL \\
\hline Óvalos concéntricos & - & - & 1 & 1 \\
\hline Piqueteado suelto & 1 & - & - & 1 \\
\hline Pisada felino & - & 2 & 4 & 6 \\
\hline Positivo de mano & - & 4 & 13 & 17 \\
\hline Punto & 2 & 4 & - & 6 \\
\hline Punto radiado & - & 1 & - & 1 \\
\hline Puntos agrupados & 2 & 2 & 1 & 5 \\
\hline Puntos en par & 1 & 1 & 1 & 3 \\
\hline Superficie pintada irregular & 1 & 2 & - & 3 \\
\hline Trazo corto individual por arrastre de dedo & 15 & 6 & 4 & 25 \\
\hline Trazos cortos paralelos por arrastres de dedos & 2 & 4 & 3 & 9 \\
\hline Tridígito & - & 10 & 6 & 16 \\
\hline Zigzag & - & 4 & - & 4 \\
\hline Zigzags paralelos & - & 1 & - & 1 \\
\hline Zoomorfo indeterminado & - & 1 & 4 & 5 \\
\hline Números de motivos & 353 & 752 & 228 & 1333 \\
\hline Número de tipos de motivos & 46 & 51 & 38 & 81 \\
\hline
\end{tabular}

Contrariamente, el sitio VQ23 es asignable a la situación opuesta (II), de un alto $\mathrm{N}$ de motivos y un bajo NTM, ya que allí se registran 363 motivos y solo 24 TM. Esto resulta interesante en tanto se trata de un sitio de tamaño intermedio y alta visibilidad, donde primó la producción de manos negativas (de diversos tamaños, desde adultos hasta bebés). Así, en este sitio la baja variabilidad de TM no depende del tamaño de la muestra, constituida por un alto $\mathrm{N}$ de motivos, sino de la intencionalidad humana de producir y reproducir un mismo TM en las paredes de este alero (fig. 6). Estos dos casos representan dos extremos opuestos dentro del continuum de situaciones (I) y (II), que registran situaciones de alta o baja variabilidad que no dependen de los respectivos tamaños de las muestras.

Otra situación distinta es la señalada en el modelo como (III), en la cual se registra un alto $\mathrm{N}$ de motivos y un alto NTM: el sitio que más se aproxima a esta situación es VQ21, donde se registra un $\mathrm{N}$ de 163 motivos expresado en $37 \mathrm{TM}$, constituyendo el mayor repertorio de TM de la localidad (fig. 6).En este caso,
Tabla 6. TM compartidos entre sectores de Viuda Quenzana. Table 6. Shared MT across Viuda Quenzana sectors.

\begin{tabular}{c|c|c|c} 
& BA & BI & CB \\
\hline TMC & 17 & 17 & 17 \\
\hline TMC & 25 & 25 & - \\
\hline TMC & 21 & - & 21 \\
\hline TMC & - & 25 & 25
\end{tabular}

la alta variabilidad de TM no puede dejar de vincularse con el alto $\mathrm{N}$ de motivos, por lo cual si bien se trata del sitio que representa la mayor variabilidad de creación de diseños, esto puede resultar parcialmente como efecto del tamaño de la muestra.

Cuando esta información es ponderada tomando en consideración el $\mathrm{N}$ de motivos de cada sitio mediante el cálculo del índice NTM/NM, se logran resultados de grano más fino. Así, se identifican sitios con un 


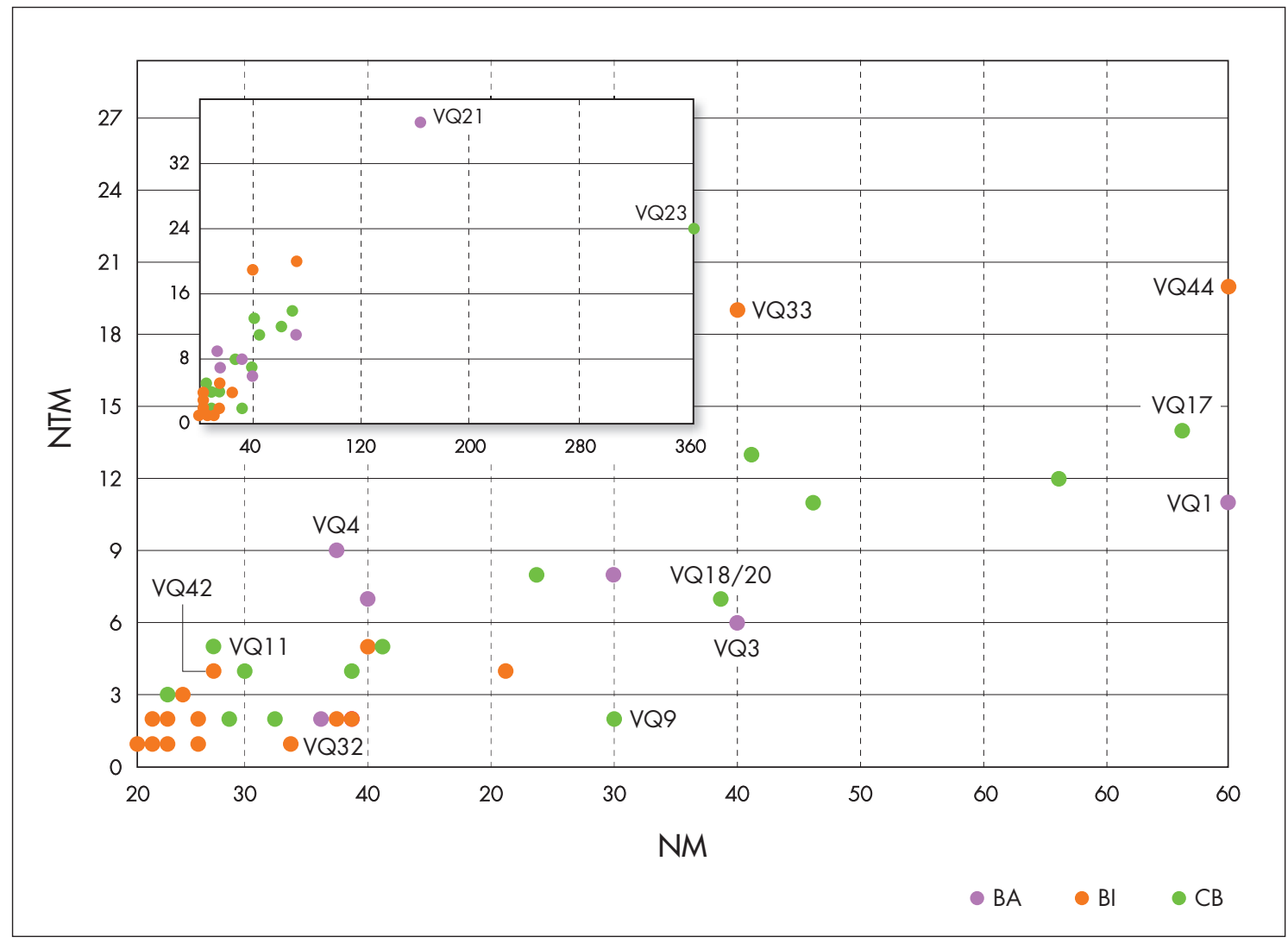

Figura 6. Gráfico de relación entre NM y NTM por sitio, para los tres sectores de Viuda Quenzana. Se indican los sitios mencionados como ejemplo en el texto. Figure 6. Chart showing the relationship between NM and NMT per site, for the three sectors at Viuda Quenzana. Sites mentioned in the text are shown in the chart.

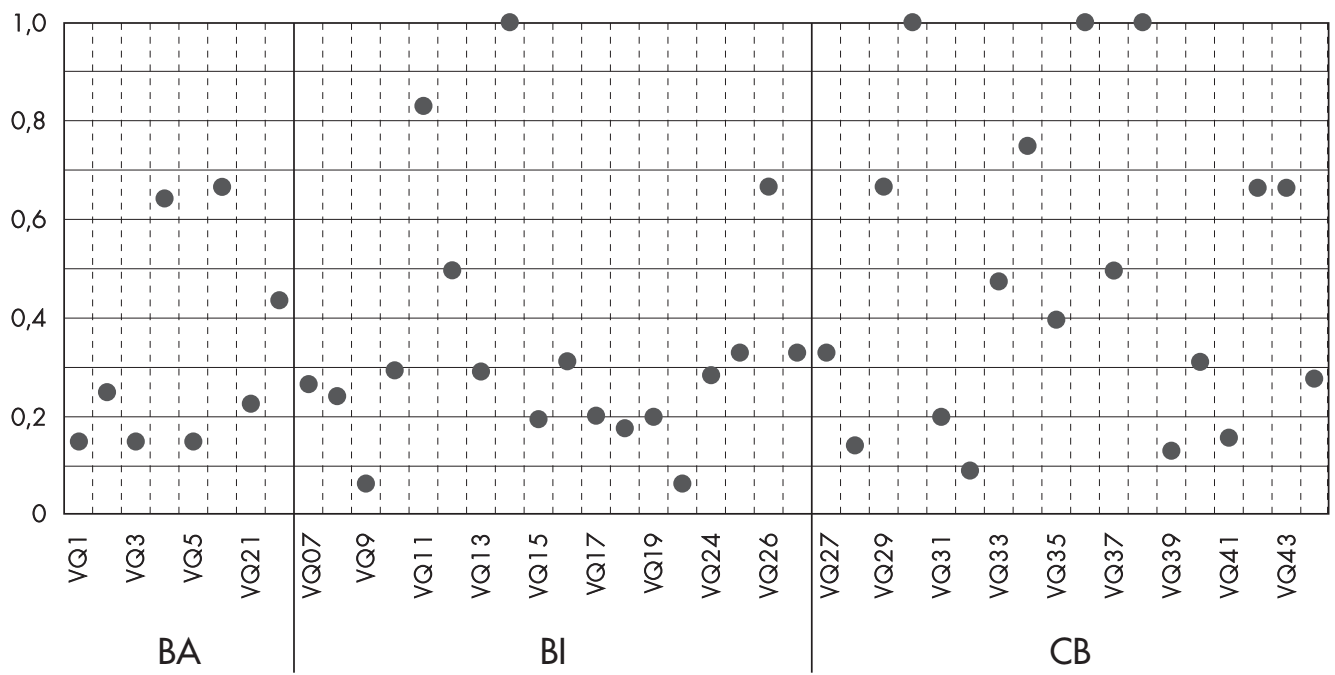

Figura 7. Índice NTM/NM por sitio y por sector de Viuda Quenzana. Figure 7. NMT/NM index per site and per sector at Viuda Quenzana. 


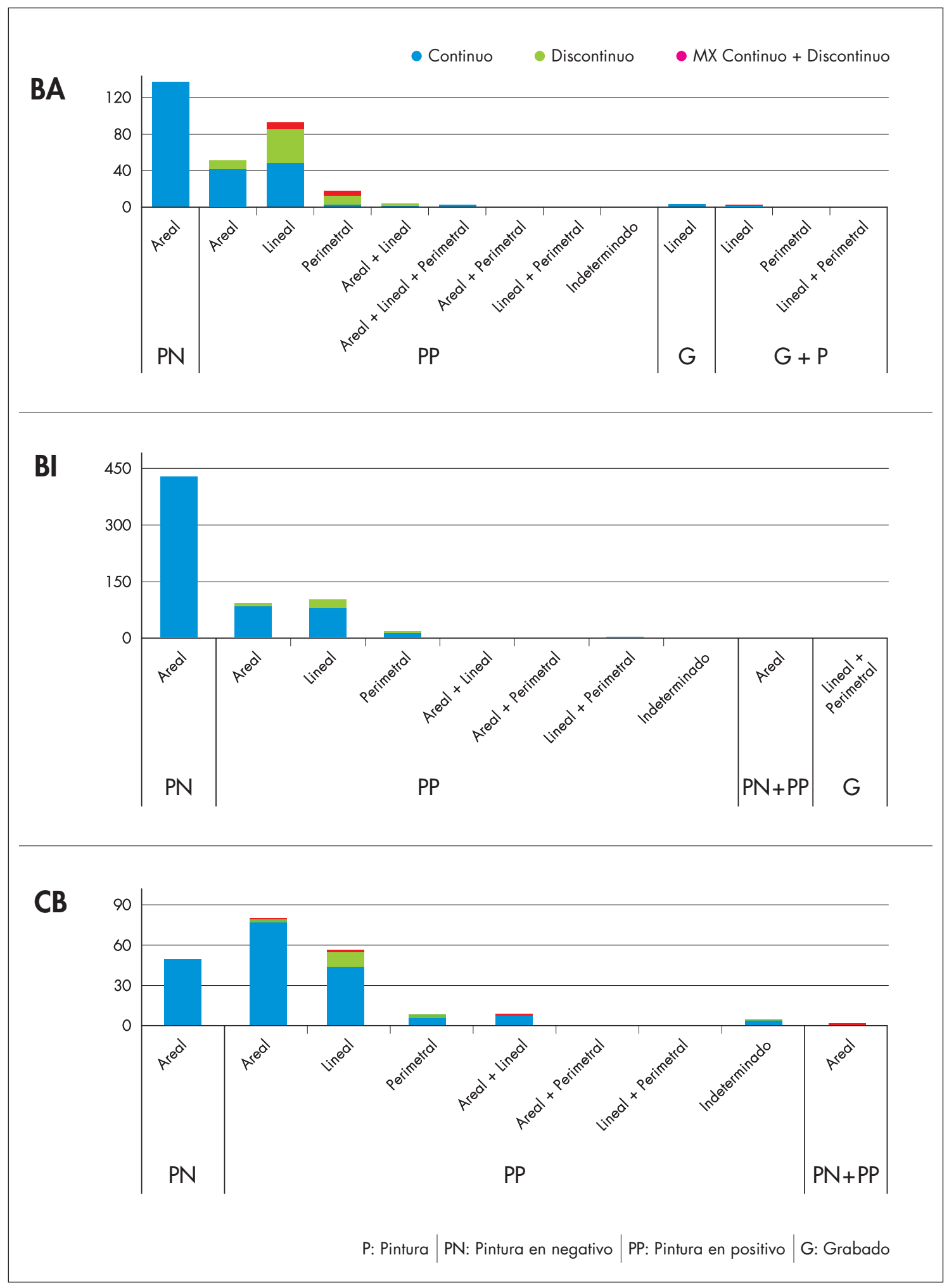

Figura 8. Técnicas artísticas de producción rupestre en Viuda Quenzana. Figure 8. Rock art production techniques at Viuda Quenzana. 
bajo índice NTM/NM, que implica una alta producción acumulada de motivos, pero baja variabilidad de diseños, tales como VQ23 (índice $\mathrm{NTM} / \mathrm{NM}=0,07$ ), VQ9 $(0,06), \operatorname{VQ} 32(0,09), \operatorname{VQ} 3(0,15), \mathrm{VQ18} / 20(0,18)$ (fig. 7). Estos casos registran una importante producción de motivos, pero con repetición de TM, lo cual sugiere que en dichos sitios primó la reiteración de determinados diseños como parte de una forma aditiva de construcción de las imágenes visuales emplazadas en los paneles (fig. 7).

Contrariamente, también se identifican en la localidad sitios con un alto índice NTM/NM, lo que implica una alta variabilidad de diseños dentro de los motivos producidos en cada sitio. Tal es el caso de VQ11 (índice NTM/NM=0,83), VQ34 (0,75), VQ42 (0,67), VQ4 $(0,64)$ (fig. 7). Estos casos implican una alta producción de TM dentro del total de motivos producidos en el sitio, lo cual sugiere que en ellos no primó la intencionalidad de repetición, sino una laxitud de reglas sociales a la hora de emplazar nuevos diseños (fig. 7).

Otro elemento central en la caracterización de la producción de imágenes rupestres de la localidad Viuda Quenzana es el relativo a las técnicas artísticas. Respecto de las técnicas generales de producción (grabado, pintura y grabado + pintura), cabe notar la existencia de tendencias específicas para cada sector (fig. 8):

a) BA y CB: predominio de la pintura positiva, seguido por la pintura negativa, el grabado inciso (escaso en $\mathrm{BA}$ y nulo en $\mathrm{CB}$ ) y las combinaciones de grabado inciso y horadado + pintura positiva (escasas en BA y nulas en $C B$ ) y pintura positiva + pintura negativa (escasas en $\mathrm{CB}$ );

b) BI: predominio de la pintura negativa, seguido por la pintura positiva y las combinaciones de grabado inciso + piqueteado (muy escasas) y pintura positiva + pintura negativa (también escasas).

Respecto de las técnicas gráficas (tratamiento gráfico de la morfología del motivo y modo de aplicación del trazo), resulta interesante notar que en los tres sectores se registra el uso de la pintura negativa para producir morfologías areales (con predominio en BA y BI). Comparativamente con la pintura negativa, la pintura positiva se usa en una mayor variedad de tratamientos gráficos de las morfologías de los motivos:

1) en BA predomina la morfología lineal, ejemplificada claramente por los motivos geométricos;

2) en BI se registra una cuasi-paridad entre morfologías lineales -ej. motivos geométricos- y morfologías areales -ej. negativo de mano;

3) en CB predomina la morfología areal, la cual está relacionada con los motivos de guanacos, entre otros.

Respecto de los modos de aplicación del trazo, la pintura negativa ha sido aplicada con trazos continuos en los tres sectores de Viuda Quenzana. Esto está especialmente ejemplificado en las abundantes manos negativas, cuya producción se constituyó mediante la aplicación de una capa de pintura continua estarcida alrededor de las manos presionadas contra el soporte. Si bien, la textura obtenida mediante el estarcido es de un punteado fino, la capa de pintura en sí es netamente continua, ya que no está fragmentada en trazos independientes o separados entre sí. La pintura positiva, en cambio, se asocia tanto a un modo de aplicación continuo, como a un modo de aplicación discontinuo. Los casos de aplicación continua de pintura positiva continua incluyen numerosos motivos geométricos, guanacos y pisadas, cuyos diseños han sido producidos utilizando trazos continuos para construir morfologías tanto areales como perimetrales o lineales. Los casos de aplicación discontinua de pintura positiva incluyen también motivos geométricos, pero elaborados utilizando trazos discretos que se traducen en la creación de elementos puntiformes, cuyo tamaño similar y gran proximidad entre sí permite asociarlos visualmente para generar un motivo identificable como tal.

\section{ELEMENTOS PARA UNA SECUENCIA LOCAL}

Se han identificado algunos tipos de motivos cuyo diseño y/o cuya posición relativa en superposiciones permite realizar asignaciones cronológicas relativas relevantes para la propuesta de una secuencia local. En primer lugar, existen dos motivos de guanaco aislados cuyo diseño -vientre abultado, cuello largo, cabeza pequeña y patas cortas- permite asociarlos al grupo estilístico B -VQ21, ya observado por Gradin \& Aguerre (1983); VQ22, con un negativo de mano rojo superpuesto. En el sitio VQ23 también se registraron numerosos elementos que contribuyen a la construcción de la mencionada secuencia: a) negativos de manos rojas y manos negras, superpuestas alternadamente, que conforman un sustrato de base sobre el cual se superponen manos blancas y otros motivos; 
b) en el hueco formado luego del desprendimiento de un bloque de la roca soporte, que removió parte de un panel en el cual se observan numerosos negativos de mano, se pintaron pisadas de felino, tridígitos y una mano positiva;

c) sobre negativos de manos rojos y negros se superpone un negativo de mano blanca, y sobre éste, se superpone parcialmente un motivo de zig-zag doble, de gran tamaño y color rojo, fue emplazado de manera vertical;

d) un motivo geométrico complejo (figura ortogonal rectilínea compleja compuesta por una clepsidra adosada a pentágonos y rombos rellenos con cuadrados) de color rojo se emplaza verticalmente y se superpone sobre una mano negativa de color negro que está en la parte superior. Además, otra mano negativa de color rojo, más distante hacia la derecha, fue parcialmente cubierta con pintura del mismo color rojo del motivo geométrico, sin generar ningún diseño distinguible;

e) figuras geométricas, tanto una rectangular vertical en amarillo como varias cuadrangulares en rojo, se ubican en un panel del soporte separado del resto de los paneles y que carece de pinturas previas. En este caso no se registran superposiciones, sino aislamiento espacial de estos motivos geométricos, que, a su vez, por la nitidez y densidad de la capa de pintura, parecen haber sido de ejecución comparativamente reciente, al igual que los motivos geométricos mencionados en "c" y "d".

f) se ha registrado un motivo de rombo con línea axial grabado sobre un negativo de mano rojo, sugiriendo que esta técnica, muy poco frecuente en la localidad, es posterior a la de pintura.

Además, en el sitio VQ44 se registró un conjunto de líneas sinuosas de morfología irregular, asociadas con pisadas de animales (tridígitos y pumas) y un conjunto de líneas rectas cortas, como segmentos irradiados a partir de un hoyuelo natural del soporte. Estos motivos se superponen con otros previos, tales como guanacos. La ejecución técnica de estos motivos es comparativamente de menor calidad que la habitualmente observada, debido a un bajo control del gesto técnico en la aplicación de la pintura. Estos indicadores -superposición y calidad técnicapermiten sugerir que podría tratarse de producciones artísticas que corresponden a momentos más recientes de la secuencia local, incluso ejecutadas por personas con menor habilidad técnica y/o menor conocimiento de las técnicas artísticas tradicionales.

Finalmente, no solo se ha constatado la presencia de grafitis con letras y números -mencionados más arriba-, sino que también se ha registrado un grafiti representando un caballo, en una de las cuevas del CB (VQ42) que probablemente haya sido habitada en momentos históricos recientes de la ocupación de Viuda Quenzana.

En síntesis, el análisis de las superposiciones permite constatar en términos generales, el cumplimiento de la serie tonal definida por Gradin \& Aguerre (1983) para la localidad, consistente en una secuenciación de motivos rojos-rojos violáceos, negros y blancos-policromos. Sin embargo, también conlleva a la ampliación de su configuración actual mediante la inclusión de, al menos, dos nuevas etapas de producción con pintura roja ejecutadas con anterioridad y posteridad a los conjuntos blancospolicromos (para un desarrollo más detallado de la secuenciación tonal de la localidad ver Acevedo 2017).

Utilizando como referencia los criterios de clasificación estilística establecidos por Gradin \& Aguerre (1983) para la localidad (grupos B, B.1 y D) y las secuencias elaboradas por Gradin et al. $(1976,1979)$ y Gradin $(1988,2001)$ para Patagonia en general, es posible arribar a tres conclusiones cronológicas sobre el arte rupestre de la localidad.

En primer lugar, los motivos de guanacos asociables al grupo estilístico B (ca. 7300 años AP; Gradin et al. 1979) evidenciarían la existencia de presencia humana previamente a los fechados radiocarbónicos disponibles para la localidad (ca. 4700 y 1200 años AP; Franco et al. 2015). Futuras excavaciones posiblemente corroboren esta datación más temprana de las ocupaciones humanas en la localidad. En segundo lugar, los motivos atribuibles al grupo estilístico B.1 (conjuntos de negativos de manos, guanacos, geométricos simples -de trazos continuos y puntiformes- $y$ pisadas), correspondientes en su mayoría a las series tonales roja-roja violácea y negra, podrían asignarse al Holoceno medio, período que cuenta con dos fechados en la localidad. En tercer lugar, los motivos geométricos complejos ubicados siempre al tope de las superposiciones se asociarían al Holoceno tardío (período que cuenta con un fechado en la localidad). 


\section{COMENTARIOS FINALES}

En este trabajo hemos presentado resultados sobre un total de 44 sitios, de los cuales 26 no eran previamente conocidos. Los registros y observaciones de campo nos han permitido distinguir tres sectores del paisaje con diferencias geomorfológicas, litológicas y altitudinales que constituyen a la localidad. Dentro de estos sectores hemos identificado el uso de distintas topografías y tamaños de sitio para el emplazamiento de imágenes rupestres. Se ha confirmado además el amplio predominio de la técnica de pintura previamente observado por Gradin \& Aguerre (1983). Esta ha sido usada sobre un soporte de ignimbritas altamente afectado por procesos de erosión catafilar, lo cual pone en alto riesgo la conservación de las imágenes. A su vez, esto aumenta el valor del registro y documentación realizados, ya que algunas de ellas están en proceso de desaparición.

Se definió un repertorio constituido por $81 \mathrm{TM}$, lo cual marca una amplia variabilidad de creación artística en la localidad, y se registró una producción total de 1333 motivos, evidenciando una importante intensidad de trabajo artístico acumulado en el tiempo. De estos 81 TM, 17 TM se comparten entre los tres sectores, constituyendo un $21 \%$ del repertorio total y un $87 \%$ de la producción total de motivos registrados en la localidad. Ello sugiere que, si bien se creó un repertorio amplio, se conformó una cierta estandarización del corpus visual al reproducir una porción específica de dicho corpus (17 TM), lo cual habría facilitado las funciones comunicativas y/o estéticas de las imágenes.

Sobre esta base, la aplicación del modelo teórico y del índice que relaciona los NTM con los NM ha permitido distinguir: a) sitios en los cuales la producción artística se orientó hacia la repetición de determinados $\mathrm{TM}$, restringiendo la variabilidad de diseños; b) sitios en los cuales la producción artística se orientó hacia la amplitud de creación de TM, en detrimento de su repetición. En términos generales, estas diferencias no parecen atribuibles a los distintos tamaños de los sitios ni tampoco a los tamaños de las muestras (i.e. $\mathrm{N}$ de motivos), por lo tanto, es posible sugerir que estas diferentes situaciones habrían respondido a la agencia humana acumulada a través del tiempo. Dicha agencia resulta evidente en tanto que la selección de una parte específica del repertorio para su repetición, a lo largo del tiempo-espacio, habría operado en el proceso de marcación de los sitios de actividades de las poblacio- nes cazadoras-recolectoras. Así, los modos de habitar el espacio (Carden 2009) habrían tenido una clara dimensión visual, creada por el emplazamiento de determinadas imágenes rupestres, cuya repetición habría sido significativa para sus productores/observadores en términos comunicacionales y/o estéticos. Sin embargo, resulta también llamativo el hecho de que un porcentaje comparativamente menor de la producción de motivos responda a un amplio número de tipos del repertorio, demostrándose claramente que, si bien la repetición de ciertos tipos era altamente habitual, no cercenaba la amplitud creativa. Así, esta alta variabilidad morfológica documentada cuantitativamente en el amplio repertorio de motivos registrados muestra la existencia de una importante fluidez creativa subyacente a la producción de imágenes rupestres en la localidad, tarea que no parece haber constituido una práctica normada. Presumiendo que su significado se hubiera mantenido con el tiempo, es posible inferir que la repetición de ciertos tipos de motivos habría facilitado la comunicación visual de contenidos de índole redundante y con alto valor social, ya que su reiteración sugiere que habrían sido compartidos por mayor cantidad de personas en su producción y visualización. Contrariamente, la creación de los otros tipos, menos frecuentes pero más variados debido a sus distintas morfologías, podría haber facilitado la comunicación de mayor pluralidad de contenidos no-redundantes. Estos tipos de motivos podrían haber tenido tanto un valor individual, si hubieran sido producidos y compartidos por menos individuos, lo cual reduce potencialmente su cualidad comunicativa, como social, si hubieran sido compartidos/visualizados por varias personas incluso al ser poco frecuentes. Esto coincide con la información arqueológica y etnográfica sobre cazadores-recolectores, en tanto que estas sociedades necesitan de una manera efectiva de transmisión de información para el desarrollo sustentable de su modo de vida. Dicha transmisión requiere de la estandarización y repetición de ciertos diseños para facilitar la comunicación, pero también tiene regulaciones comparativamente laxas en algunas de sus prácticas artísticas (lo cual da lugar a la variabilidad de sus diseños) (e.g. Boas 1955; Leroi-Gourhan1967; Gamble 1982; Fiore 2008; entre otros).

A su vez, la secuencia local aquí presentada, en combinación con las series tonales (Gradin \& Aguerre 1983; Acevedo 2017) demuestra que, además de las importantes reiteraciones de determinados TM, las poblaciones habitantes de la localidad generaron también adiciones 
al repertorio de motivos, produciendo aumentos en la variabilidad de diseños. Esta variedad de diseños puede vincularse con localidades vecinas (e.g., La Gruta, La Martita, El Verano, La María y El Ceibo), que presentan largas secuencias de producción rupestre y con las que comparte muchos elementos en común, por ejemplo: producciones dominadas por conjuntos de negativos de manos, con presencia importante de representaciones de guanacos aislados y conjuntos de guanacos, a los que se suman motivos geométricos puntiformes y, en forma menos frecuente, negativos de pie, de pata de choique, antropomorfos y motivos geométricos complejos, entre otros (Cardich 1987; Duran 1983-85; Aguerre 1987, 2003; Franchomme 1987; Pauneroet al. 2005; Franco et al. 2010). Estas afinidades llevan a plantear la necesidad de analizar el arte rupestre de Viuda Quenzana en forma integrada con la producción rupestre del Sur del Macizo del Deseado.

Estas distintas tendencias de producción de imágenes a escala de sitio y localidad responden posiblemente a cuestiones vinculadas con el uso del espacio y la construcción de paisajes en la localidad, las que serán exploradas a futuro para arrojar nueva luz sobre el vínculo entre las personas, los lugares y la materialidad de las imágenes.

AgRADECIMIENTOS Este trabajo fue financiado por los proyectos PIP 1122012010447CO, РІСТ-2015-2038 у UвАСут 20020130100664 BA, dirigidos por la Dra. Nora V. Franco. El trabajo de investigación del Lic. Agustín Acevedo fue financiado por una Beca Interna de Doctorado del Conicet. A Minera Piedra Grande s. A. y todo su personal por su gentileza al brindarnos hospedaje y apoyo logístico esenciales para nuestros relevamientos. Al Dr. Claudio Iglesias por sus valiosos aportes sobre la geología regional. A Nora Franco, George Brook, Natalia Cirigliano, Pablo Ambrústolo, Lucas Vetrisano y Rafael Alegre por su asistencia en los trabajos de campo. A Annette Aguerre por su generoso aporte de información sobre Viuda Quenzana, fruto de sus trabajos pioneros en la localidad. A la Secretaría de Turismo de la Municipalidad de Gobernador Gregores, especialmente a Pablo Ramírez, por la ayuda logística. A los/las evaluadores anónimos/as por sus comentarios y a las editoras invitadas por su tarea editorial. Este trabajo está dedicado a la memoria de nuestra querida colega Mariana De Nigris, con quien compartimos la pasión por la arqueología patagónica y de nuestro compañero de equipo Carlos Pesqueira, quien prestó invaluable ayuda durante la campaña de 2014.

\section{NOTAS}

${ }^{1} \mathrm{Si}$ bien el cañadón no cuenta actualmente con un flujo de agua constante, en su interior se registró la presencia de numerosas aguadas y mallines.

${ }^{2} \mathrm{Se}$ define TM como un conjunto recurrente de atributos morfológicos que permiten la clasificación de varios casos de motivos en una misma categoría de diseño, la cual es morfológicamente distinta a otras categorías (Hernández Llosas 1985, Aschero 1988, Fiore 2011).

${ }^{3}$ Nótese que este índice es sensible al tamaño de la muestra, razón por la cual una muestra con un $\mathrm{N}$ bajo puede generar un resultado muy alto (cercano a 1) si es que los pocos motivos de la muestra corresponden a pocos TM.

${ }^{4}$ Dada la existencia diferencias de criterio al momento de definir los sitios rupestres, los 12 sitios originalmente identificados por Gradin y Aguerre (1983), actualmente se subdividen en 14 sitios. Las principales diferencias radican en la definición de los sitios Quenzana 2 (Gradin \& Aguerre 1983), actualmente VQ2 y VQ3, y Quenzana 3 (Gradin \& Aguerre 1983), actualmente VQ4, VQ5 y VQ6.

${ }^{5}$ Se prospectó un total de 25 cuevas/aleros en la pared Norte y 30 cuevas/aleros en la pared sur del Cañadón Bajo, lo cual permitió registrar arte rupestre en 18 de ellas, 7 en pared Norte y 11 en pared Sur.

${ }^{6}$ Con excepción de VQ33 cuyo acceso se encuentra casi totalmente obstruido por un bloque de gran tamaño y VQ44 que presenta un talud pronunciado.

\section{REFERENCIAS}

Acevedo, A. 2017. Arte, composición visual y paisaje. Un estudio de la producción rupestre de los grupos cazadoresrecolectores de la región extremo sur del macizo del Deseado, Provincia de Santa Cruz, Argentina.Tesis para optar al grado de Doctor en Antropología, Universidad de Buenos Aires, Buenos Aires.

Acevedo, A., Fiore, D., Franco, N. V. \& Ocampo, M. 20122014. Arte y espacio. Estructuración de los repertorios de arte rupestre en los cañadones Yaten Guajen y El Lechuza (margen norte del río Santa Cruz, Patagonia, Argentina). Mundo de Antes 8: 9-33.

Aguerre, A. M. 1987. Investigaciones arqueológicas en el "Área de La Martita", Departamento Magallanes, Provincia de Santa Cruz. En Comunicaciones de las Primeras Jornadas de Arqueología de la Patagonia, pp. 11-16. Rawson: Dirección Impresiones Oficiales Provincia Chubut.

Aguerre, A. M. 2003. La Martita: ocupaciones de 8000 años en la Cueva 4. En Arqueología y paleoambiente en la Patagonia santacruceña argentina, A. M. Aguerre, Ed., pp. 153-204. Buenos Aires: Nuevo Offset. 
Aschero, C. 1988. Pinturas rupestres, actividades y recursos naturales; un encuadre arqueológico. En Arqueología contemporánea argentina. Actualidad y perspectivas, $\mathrm{H}$. Yacobaccio, Ed., pp. 109-145. Buenos Aires: Búsqueda.

Aschero, C. 1997. De cómo interactúan emplazamientos, conjuntos y temas. Actas XI Congreso Nacional de Arqueología Argentina. Revista del Museo de Historia Natural de San Rafael 16 (1-4): 17-28.

Aschero, C. 2000. El poblamiento del territorio. En Nueva historia argentina. Los pueblos originarios y la conquista, M. Tarragó, Ed., Volumen 1, pp. 16-59. Buenos Aires: Sudamericana.

BEDNARIK, R. 2001. Rock art science. The scientific study of Palaeoart. Turnhout: Brepols.

BoAs, F. 1955. Primitive art. Nueva York: Dover Press.

CARDEN, N. 2009. Imágenes a través del tiempo. Arte rupestre y construcción social del paisaje en la Meseta Central de Santa Cruz. Buenos Aires: Sociedad Argentina de Antropología.

Cardich, A. 1987. Arqueología de Los Toldos y El Ceibo (Provincia de Santa Cruz, Argentina). Estudios Atacameños 8: 98-117.

DURÁN, V. 1983-1985. Arte rupestre de los cazadores patagónicos en "El Verano", Área de La Martita, Departamento Magallanes, Provincia de Santa Cruz. Anales de Arqueología y Etnología 38-40: 43-75.

Fiore, D. 2002. Bodypainting in Tierra del Fuego. The power of images in the uttermost part of the world. Tesis para optar al grado de Doctor en Arqueología, Universidad de Londres, Londres.

Fiore, D. 2006. Poblamiento de imágenes: arte rupestre y colonización de la Patagonia. Variabilidad y ritmos de cambio en tiempo y espacio. En Tramas en la piedra. Producción $y$ usos del arte rupestre, D. Fiore \& M. Podestá, Eds., pp. 43-61. Buenos Aires: AINA, SAA \& WAC.

FIORE, D. 2008. Body painting and visual practice. The creation of social identities through image making and display in Tierra del Fuego (Southern South America). En Archaeologies of art. Time, place and identity, I. Domingo, D. Fiore \& S. May, Eds., pp. 243-266. California: Left Coast Press.

Fiore, D. 2009. La materialidad del arte. Modelos económicos, tecnológicos y cognitivo-visuales. En Perspectivas actuales en arqueología argentina, R. Barberena, K. Borrazo \& L. A. Borrero, Eds., pp. 121-154. Buenos Aires: ConICETIMIHICIHU.

Fiore, D. 2011. Materialidad visual y arqueología de la imagen. Perspectivas conceptuales y propuestas metodológicas desde el sur de Sudamérica. Boletín del Museo Chileno de Arte Precolombino 16 (2): 101-119.

FIORE, D. 2016. Las dimensiones espaciales del arte parietal. Estado actual de las investigaciones desde el Cono Sur y propuesta de síntesis metodológica. En Imágenes rupestres, lugares y regiones, F. Oliva, A. M. Rocchietti \& F. Solomita, Eds., pp. 51-62. Rosario: CEAR, Facultad de Humanidades y Artes, Universidad Nacional de Rosario.
Fiore, D. \& Acevedo, A. 2016. El trabajo del arte. Una evaluación de la inversión laboral en la producción de arte rupestre: el caso del cañadón Yaten Guajen (Santa Cruz, Patagonia, Argentina). En Imágenes rupestres, lugares y regiones, F. Oliva, A. M. Rocchietti \& F. Solomita, Eds., pp. 485-504. Rosario: CEAR, Facultad de Humanidades y Artes, Universidad Nacional de Rosario.

Fiore, D. \& Acevedo, A. 2017 Ms. Paisajes rupestres. la identificación de patrones de producción y distribución de arte parietal en escalas espaciales amplias (Cañadón Yaten Guajen, Santa Cruz, Patagonia Argentina). <https://www. researchgate.net/publication/329196918_Paisajes_rupestres_La_identificacion_de_patrones_de_produccion_y_distribucion_de_arte_parietal_en_escalas_espaciales_amplias_ canadon_Yaten_Guajen_Santa_Cruz_Patagonia_Argentina_Revista_Arqueologia_242> [consultado: 22-07-2019].

Franchomme, J. M. 1987. L'art rupestre de Patagonie: quelques sites prehistoriques du Plateau Central, Province de Santa Cruz, Argentine. Tesis para optar al grado de Doctor, Universidad de París x, Nanterre.

Franco, N. V., Martucci, M., Ambrústolo, P., Brook, G., Mancini, M. V. \& Cirigliano, N. A. 2010. Ocupaciones humanas correspondientes a la transición PleistocenoHoloceno al sur del macizo del Deseado: el área de La Gruta (Provincia de Santa Cruz, Argentina). Relaciones de la Sociedad Argentina de Antropología 35: 301-308.

Franco, N., Ambrústolo, P., Acevedo, A., Cirigliano, N. \& Vommaro, M. 2013. Prospecciones en el sur del macizo del Deseado (Provincia de Santa Cruz). Los casos de La Gruta y Viuda Quenzana. En Tendencias teórico-metodológicas y casos de estudio en la Arqueología de la Patagonia, F. Zangrando, R. Barberena, A. Gil, G. Neme, M. Giardina, L. Luna, C. Otaola, S. Paulides, L. Salgán \& A. Tívoli, Eds., pp. 371-378. Buenos Aires: Altuna.

Franco, N., Brook, G., Mancini, M. V. \& Vetrisano, L. 2015. Changes in lithic technology and environment in southern continental Patagonia: the Chico and Santa Cruz River basins. Quaternary International 422: 57-65.

Gamble, C. 1982. Interaction and alliance in Palaeolithic society. Man 17: 92-107.

Gell, A. 1998. Art and agency. An anthropological theory. Oxford: Clarendon Press.

Gradin, C. J. 1978. Algunos aspectos del análisis de las manifestaciones rupestres. Revista del Museo Provincial de Neuquén 1: 120-133.

Gradin. C. J. 2001. El arte rupestre de los cazadores de guanaco de la Patagonia. En Historia argentina prehispánica, E. Berberián \& A. Nielsen, Eds., pp. 839-874. Córdoba: Brujas.

Gradin, C. \& Aguerre, A. M. 1983. Arte rupestre del "Área de La Martita” sección del departamento Magallanes provincia de Santa Cruz. Relaciones de la Sociedad Argentina de Antropología xv: 195-223.

Gradin, C., Aschero, C. \& Aguerre, A. M. 1976. Investigaciones arqueológicas en la Cueva de las Manos, estancia 
alto río Pinturas (Provincia de Santa Cruz). Relaciones de la Sociedad Argentina de Antropología x: 201-250.

Gradin, C., Aschero, C. \& Aguerre, A. M. 1979. Arqueología del área río Pinturas (Provincia de Santa Cruz). Relaciones de la Sociedad Argentina de Antropología XIII: 183-227.

HARMAN, J. 2008 [2005]. Using decorrelation stretch to enhance rock art images. <http://www.dstretch.com/ AlgorithmDescription.html> [consultado: 22-07-2019].

Hernández Llosas, M. I. 1985. Diseño de investigación para representaciones rupestres. En Programa de investigación $y$ documentación de arte rupestre argentino, pp. 9-65. Buenos Aires: FECIC.

Hernández Llosas, M. I. 2009. Rock art research and beyond. Archaeological inquiry, political responsibility and community involvement in the process of protecting and presenting rock art sites. En $L$ 'art parietal: conservation, mise en valeur, communication: actes du colloque international des Eyzies-de-Tayac, pp. 63-76. Les Eyzies: SAMrA.

Leroi-Gourhan, A. 1967. Treasures of prehistoric art. Nueva York: H. Abrams Publisher.

Mithen, S. 1988. To hunt or to paint: animals and art in the upper Palaeolithic. Man 23 (4): 671-695.

MolinA, M. 1972. Arqueología patagónica-arte rupestre austral. Antiquitas XII-XIII: 24-30.
Morphy, H. (ed.) 1989. Animals into art. Londres: Routledge. OuzMAn, S. 1998. Toward a mindscape of landscape: rock-art as expression of world-understanding. En The archaeology of rock-art, C. Chippindale \& P. Taçon, Eds., pp. 30-41. Cambridge: Cambridge University Press.

PanZa, J. L. \& MARín, G. 1998. Hoja geológica 4969-I Gobernador Gregores, Provincia de Santa Cruz. Programa Nacional de Cartas Geológicas de la República Argentina 1:250.000. Boletín $N^{\circ} 239$. Buenos Aires: Secretaría de Minería de la Nación. Dirección Nacional del Servicio Geológico.

Paunero, R., Frank, A., Skarbun, F., Rosales, G., Zapata, G., Cueto, M. E., Paunero, M. F., Martínez, D., López, R., Lunazzi, N. \& Del Giorgio, M. 2005. Arte Rupestre en Estancia La María, Meseta Central de Santa Cruz: Sectorización y contextos arqueológicos. Relaciones de la Sociedad Argentina de Antropología 30: 147-168.

RE, A. 2010. Representaciones rupestres en mesetas altas de la provincia de Santa Cruz. Circulación de información en espacios de uso estacional. Tesis para optar al grado de Doctor en Antropología, Universidad de Buenos Aires, Buenos Aires.

Rosenfeld, A. 1988. Rock art conservation in Australia. Canberra: Australian Government Publication Service. 